\title{
Pathogen Associated Molecular Patterns, Pattern Recognition Receptors and Pediatric Sepsis
}

\author{
Lesley Doughty*
}

\author{
Division of Critical Care Medicine, Cincinnati Children's Hospital Medical Center, University of Cincinnati School of \\ Medicine, USA
}

\begin{abstract}
The mortality of septic shock in the pediatric population has improved over the last 2 decades with better supportive care however it still remains unacceptably high. Exaggerated inflammatory responses early in septic shock have been associated with poor outcomes. Regulation of the magnitude of the early inflammatory response is not well understood. The earliest aspect of the inflammatory response to pathogens is the innate immune response which is important to pathogen containment. Elements of the innate immune system activate the adaptive immune system in an antigen-specific way which leads to pathogen-specific protection and lasting immunologic memory to prevent subsequent infection. Pattern recognition receptors (PRRs) are evolutionarily conserved receptors on multiple types of innate immune cells and are capable of responding to highly conserved components of pathogens called pathogen associated molecular patterns (PAMPs). Numerous PRRs have been defined and are present on the cell surface as well as in the cytosol. These receptors fall into several classes called Toll-like receptors which are expressed on the cell surface or on the endosomal plasma membrane, $\mathrm{C}$ type lectin receptors and scavenger receptors which are only present on the cell surface. Other PRRs are present in the cytosol and including NOD-like receptors which can aggregate to form inflammasomes and RIG1 like receptors. Pathogenic microorganisms are extremely diverse however there are some common patterns repeated in components of structures such as the cell wall. PRRs can respond to PAMPs comprised of proteins, lipids, and carbohydrates, DNA and RNA. Numerous PAMPs have been described for many classes of pathogenic microorganisms such as Gram negative bacteria, Gram positive bacteria, viruses, fungi, and protozoa. The interactions between PRRs and PAMPs comprise the earliest immune responses to foreign substances and are critical for pathogen containment and amplification of the full repertoire of the immune response. There are developmental differences in the immune systems of infants and children compared to adults. The innate immune system matures much earlier than the adaptive immune response and as a result infants and young children may be more reliant on their innate immune system. For this reason it important to fully understand the key elements of the innate immune response including the many categories of PRRs and their cognate PAMPs. As these interactions are very early in the immune response, they are particularly relevant targets for therapeutic intervention. Below is a discussion of the major classes of PRRs, their expression, ligands, and signaling pathways as well as the major classes of PAMPs that activate them.
\end{abstract}

Keywords: Sepsis, pediatric, pathogen associated molecular patterns, pattern recognition receptors, Rig like helicases, inflammasomes, NOD like receptors, Scavenger receptors, C type lectins.

\section{INTRODUCTION}

Septic shock is the leading cause of death in infants and children throughout the world. In the USA alone, deaths from septic shock even surpass deaths from cancer [1,2]. Although mortality from septic shock in the pediatric population has improved from nearly $100 \%$ in the 1960 's to approximately $10 \%$ in this last decade with the impact of current supportive care, greater than 4,000 deaths per year still occur. In adults the mortality is much worse at $30-40 \%$ despite similar improvements in supportive care [3, 4]. Unfortunately, our understanding of how bacterial infection can progress to sepsis despite antibiotics is still poor. Septic shock is an example of massive activation of many components of the innate immune system. The highest morbidity and mortality in both children and adults with

*Address correspondence tothis author at the Division of Critical Care Medicine MLC 2005, Cincinnati Children's Hospital Medical Center, 3333 Burnet Ave, Cincinnati, OH 45229, USA; Tel: 513-636-4259;

Fax: 513-636-4267; E-mail: lesley.doughty@cchmc.org sepsis occurs when dysregulation of the pro-and antiinflammatory response is present [5-11]. What determines the quality or magnitude of an inflammatory response is not well characterized. A frightening reality is that otherwise healthy, well nourished children and adults can develop septic shock and succumb despite aggressive and multisystem supportive care. Very good examples of this are meningococcemia, group A $\beta$ hemolytic streptococcal sepsis, and severe necrotizing community acquired pneumonia/sepsis which often occur in otherwise healthy individuals. Very little is known about the causes for the explosive inflammatory responses in these settings and even less is known about causes for vulnerability opening the door for such events in otherwise healthy people. In order to make further advances in prevention and/or survival from septic shock it is critical to understand the nature of the early immune response to pathogens. This manuscript will address the cellular receptors involved in responses to pathogens in the initial phase of host - pathogen interaction. 
The earliest aspect of the inflammatory response activated in septic shock is the innate immune system. This activation is critical for rapid initiation of a robust inflammatory response when the host is confronted with a pathogen challenge. In essence, cells of this component of the immune response are the first responders to invading pathogens. Pathogens from all categories including bacteria, viruses, fungi, and parasites can activate innate immune cells. In contrast, the adaptive immune system is initiated by the innate immune response in an antigen-specific way culminating in pathogen-specific protection and lasting immunologic memory necessary to prevent subsequent infection [12-14].

An enormous amount of research over the last 20 years has been devoted to defining the key aspects of the innate immune response responsible for inducing host response to pathogens. Pattern recognition receptors (PRRs) are evolutionarily conserved receptors capable of responding to highly conserved components of pathogens called pathogen associated molecular patterns (PAMPs). These molecular structures can derive from cell wall contents including lipopolysaccharide (LPS), peptidoglycan (PGN), other cellular components including flagellin, microbial RNA and DNA, viral structures such as envelopes and capsids, as well as many other proteins, glycoproteins and glycolipids. In addition PRRs can respond to some host derived "danger signals" that include molecules exposed/released during cellular stress or tissue injury [12-18].

PRRs are present on innate immune cells including dendritic cells, monocytes, macrophages, neutrophils, cytotoxic NK cells and epithelial cells. PRRs can be expressed on cell surfaces, in the cytoplasm, or in endosomes and have specificity for PAMPs from a variety of sources $[12,13]$. The innate immune response can be initiated by PRR-mediated recognition of a vast array of PAMPs expressed or released by bacterial, viral, fungal, and parasitic pathogens. PRRs are not pathogen specific instead they are PAMP specific and as such can bind molecular structures common to many pathogens $[12,13]$. When PAMPs are recognized by PRRs, intracellular signaling cascades are activated resulting in expression of genes encoding for various elements of the inflammatory response including cytokines, chemokines, and type 1 interferons (IFNs) including IFN $\alpha$ and IFN $\beta$. The result of PAMPinduced PRR signaling is amplification of cell responses to pathogen challenge, cell trafficking into infected sites, and intercellular communication to provide an effective protective response to pathogen invasion $[12,13]$.

The definition of sepsis and septic shock as well as management of this syndrome has been described in the other chapters of this supplement. In this section, key aspects of the innate immune response that sense and react to pathogens will be discussed.

Significant advances in understanding developmental differences in the innate immune response in the newborn which result in excess vulnerability to severe infection and catastrophic septic shock. Several differences in innate and adaptive immunity have been defined in newborns which are summarized in a recent review by Wynn et al. [19, 20]. Upregulation of the PRR called Toll like receptors (TLRs) (reviewed below) has been demonstrated in cord blood monocytes associated with gestational age. Beyond that, no differences in expression of PRRs on cord blood or circulating monocytes have been demonstrated between newborns and adults $[21,22]$. Despite this, stimulation of the innate immune responders results in a skewed end product favoring an anti-inflammatory cytokine response to PAMPs when compared to the adult response [22, 23]. This antiinflammatory phenotype leads to decreased bacterial clearance and increased mortality in a newborn mouse model of peritonitis [24]. The adaptive immune response develops much later in infancy and as such the newborn is heavily reliant on the innate immune response $[19,20]$.

Much less is known about any differences in immune responsiveness in children compared to adults. It is clear from the sepsis literature that the pediatric population has dramatically more favorable outcome from septic shock when compared to the adult population [25, 26]. Whether this reflects developmental differences in immune responses or simply the resilience of children is not known. It appears that a skewed anti-inflammatory cytokine response to PAMPs persists into childhood based on responses of peritoneal macrophages (from humans) and circulating monocytes [27-29]. Others have shown that the adaptive immune response continues to evolve into the second decade of life. As in the newborn, the infant and child may continue to depend on the innate immune response more heavily than the adult. For this reason it important to fully understand the key elements of the innate immune response including the many categories of PRRs and their cognate PAMPs. Below is a discussion of the major classes of PRRs, their expression, ligands, and signaling pathways. In addition, some of the classic PAMP structures will be reviewed.

\section{TOLL-LIKE RECEPTORS}

TLRs are a highly conserved group of type 1 transmembrane receptors that have been extensively studied and well characterized. Currently 11 human and 13 mouse TLRs have been described and all share several features [13, 14, 16-18]. As transmembrane proteins, each has an extracellular and a cytoplasmic domain. The extracellular domain contains leucine-rich repeat (LRR) motifs that are responsible for PAMP recognition. The cytoplasmic domain is homologous to the cytoplasmic domain of the IL-1 receptor and as such is called the Toll/IL-1 receptor (TIR) homology domain [30]. This aspect of the TLR is essential for downstream signaling. TLRs can be expressed at the cell surface or intracellularly in endosomes [12, 13, 16, 17].

TLRs can be characterized based on the type of molecules recognized. Lipid moieties are recognized by TLRs expressed on the cell surface including TLR1, TLR2, TLR4, and TLR6. Nucleic acids are recognized by TLR3, TLR7, TLR8, and TLR9 which are expressed in the endosomes (Table 1). Some protein ligands can be recognized by TLR 5 and possibly TLR 11 and TLR 10 is less well characterized. Importantly, TLRs can interact directly with PAMPs or indirectly through interaction with PAMPbinding proteins [18]. For example LPS must be bound to LPS binding protein (LBP) and CD14 at which point it is transferred to myeloid differentiation protein 2 (MD2) prior to activating TLR4 [17]. There are also some data that implicate CD14, CD36, and Dectin-1 involvement in TLR2 
Table 1. Pattern Recognition Receptors

\begin{tabular}{|c|c|c|c|}
\hline \multicolumn{4}{|c|}{ Toll-like Receptors } \\
\hline \multirow[t]{2}{*}{ TLR2/TLR6 } & Cell Surface & Diacyl Lipopolypeptides & Mycoplasma \\
\hline & & Lipotechoic Acid & Gram Positive Bacteria \\
\hline \multirow{7}{*}{ TLR2 } & & Peptidoglycan & Gram positive and negative bacteria \\
\hline & & Lipoarabinomannan & Mycobacteria \\
\hline & & Porins & Neisseria \\
\hline & & GPI-Mucin & Protozoa \\
\hline & & Phospholipomannan & Candida \\
\hline & & Zymosan & Fungi \\
\hline & & $\beta$ Glucan & Fungi \\
\hline TLR3 & Endosome & dsRNA & Viruses-Influenza, CMV, Reo \\
\hline \multirow[t]{2}{*}{ TLR4 } & Cell Surface & LPS & Gram Negative Bacteria \\
\hline & & Envelope glycoproteins & Viruses (RSV, VSV) \\
\hline TLR9 & Endosome & CpG DNA & Virus, Bacteria, Protozoa \\
\hline \multicolumn{4}{|c|}{ RIG1-like Receptors } \\
\hline RIG1 & Cytoplasm & dsRNA short (5' triphosphate) & Viruses (IAV, RSV, HCV) \\
\hline MDA5 & Cyotplasm & dsRNA long & Viruses (picorna, norovirus) \\
\hline \multicolumn{4}{|c|}{ NOD-like Receptors } \\
\hline NOD1 & Cytoplasm & Diaminopimelic Acid & Gram Negative Bacteria \\
\hline NOD2 & Cytoplasm & MDP & $\begin{array}{c}\text { Gram Positive and Negative } \\
\text { Bacteria }\end{array}$ \\
\hline NALP1 & Cytoplasm & MDP & $\begin{array}{c}\text { Gram Positive and Negative } \\
\text { Bacteria }\end{array}$ \\
\hline NALP3 & Cytoplasm & ATP, Urate Crystals, RNA, DNA & Viruses, Bacteria, and host \\
\hline IPAF & Cytoplasm & Flagellin & Salmonella, Legionella, Listeria \\
\hline \multicolumn{4}{|c|}{ Scavenger Receptors } \\
\hline SR-A 1/11 & Cell Surface & LPS, LTA, CpG DNA & E. coli, $S$. aureus, $N$. meningitidis \\
\hline
\end{tabular}


Table 1. Contd....

\begin{tabular}{|c|c|c|c|}
\hline MARCO & Cell Surface & LPS, LTA, CpG DNA & S. pneumoniae, $N$. meningitidis \\
\hline SR-B (CD-36) & Cell Surface & LPS, LTA, CpG DNA & Gram positive bacteria \\
\hline \multicolumn{4}{|l|}{ C-type Lectins } \\
\hline Mannose Receptor & & Capsular Polysaccharides, ManLam & Mycobacteria, C. albicans \\
\hline DC-SIGN & Cell Surface & $\begin{array}{c}\text { High mannose, fucose, Lewis } \\
\text { Antigen }\end{array}$ & $\begin{array}{l}\text { H. pylori, S. pneumoniae, } \\
\text { Mycobacteria, C. albicans }\end{array}$ \\
\hline Dectin-1 & Cell Surface & $\beta 1,3$-glucan & $\begin{array}{c}\text { Mycobacteria, C. albicans, } A \text {. } \\
\text { fumigatus }\end{array}$ \\
\hline PKR & Cytoplasm & dsRNA & Viruses \\
\hline DAI & Cytoplasm & DNA & Viruses \\
\hline
\end{tabular}

(Adapted from [1-3]).

interaction with specific ligands and may confer some specificity between di and triacylated lipopeptides and contribute to sensitivity to ligands [31-35]. Upon sensing PAMPs TLR oligomerize to initiate signaling. Some TLRs homodimerize (TLR3, TLR4, TLR5, TLR7, TLR8, TLR9, and TLR11) while others heterodimerize (TLR1/TLR2, TLR2/TLR6) to initiate signaling. In the case of TLR2 specificity is altered based on heterodimerization with TLR1 versus TLR6 in that TLR1/TLR2 recognizes triacyl lipopolypeptides and TLR2/TLR6 recognizes diacyl lipopolypeptides [13, 17].

Some attempts to define ligands for various TLRs, have been confounded by impurities in putative ligands. Preparations of bacterial products and bacterial-derived recombinant proteins can contain low level impurities including LPS, lipopeptides, and even bacterial DNA. As a result ligand and receptor specificity has sometimes been misleading and further purification of reagents resulted in altered conclusions [36-38]. Multiple approaches are used to eliminate impurities and over the last 10 years purity of PAMP preparations have continued allowing clarification of earlier data and controversies.

The protein cascade activated by ligand binding is very similar to that used by the IL-1R (Fig. 1). Once activated the intracellular TIR domain of the TLR recruits and interacts with adaptor proteins also containing the TIR domain such as myeloid differentiation primary response protein 88 (MyD88) and MyD88 adaptor-like protein (MAL), TIR domain-containing adaptor inducing IFN $\beta$ (TRIF), and TRIF-related adaptor molecule (TRAM). Individual TLR ligands can induce different types of responses in part because of the selective use of these adaptor molecules which activate a cascade of signaling that ultimately leads to activation of the transcription factors activator protein 1 (AP1), nuclear factor $\kappa \mathrm{B}(\mathrm{NF \kappa B})$, and interferon-regulatory factors (IRFs) which are the direct inducers of inflammatory gene products $[14,15,17,18,39-41]$.
MyD88 plays a prominent role in signaling by all TLRs except TLR3. The adaptor protein MAL is necessary for the homophilic association between the TIR domains of MyD88 and TLR2 and TLR4. MAL does not appear to be required for MyD88 interaction with other TLRs including TLR5, TLR7, TLR8, and TLR9. The interaction between TLRMAL-MyD88 recruits the IL-1R associated kinase (IRAK) kinase family including IRAK1, IRAK2, and IRAK4 [14, 17, 18]. Through sequential phosphorylations the cluster of IRAK molecules dissociates from MyD88 and interacts with TNFR associated factor 6 (TRAF6). Both mouse and human data have demonstrated that IRAK4 is an essential molecule in this process $[13,14,17,18,42-44]$. TRAF6 is a ubiquitin ligase and together with other members of the ubiquitin enzyme complex (Ubc13, Uev1A) catalyze the synthesis of lysine 63-linked polyubiquitin chains resulting in autoubiquitination of TRAF6 and ubiquitination of transforming growth factor-activated protein kinase 1 (TAK1) as well as the NFKB essential modulator (NEMO). TAK1 binding protein 2 (TAB2) and TAB3 associate with this complex leading to activation of inhibitory $\kappa \mathrm{B}$ kinase (IKK) and the MAPK pathway $[12,13,16,17]$. Activation of IKK leads to I $\kappa \mathrm{B}$ degradation and translocation of $\mathrm{NF \kappa B}$ to the nucleus which activates many genes important to the inflammatory response. TAK1 mediated phosphorylation of proximal members of the MAPK kinase family ultimately results in phosphorylation of p38 and JNK leading to activation of the transcription factor AP-1 which also activates many inflammatory genes [12, 13, 16, 17].

An MyD88-independent signaling pathway downstream of TLR signaling was discovered using MyD88 deficient mice. The adaptor molecule recruited to the TLR TIR domain is TRIF and this pathway is only used by TLR3 and TLR4. Similar to MAL, TRAM3 is another adaptor protein necessary for interaction between TRIF and the TIR domain of TLR4 but not TLR3. Therefore TLR4 unlike all other TLRs can signal both through the MyD88 and the TRIF 


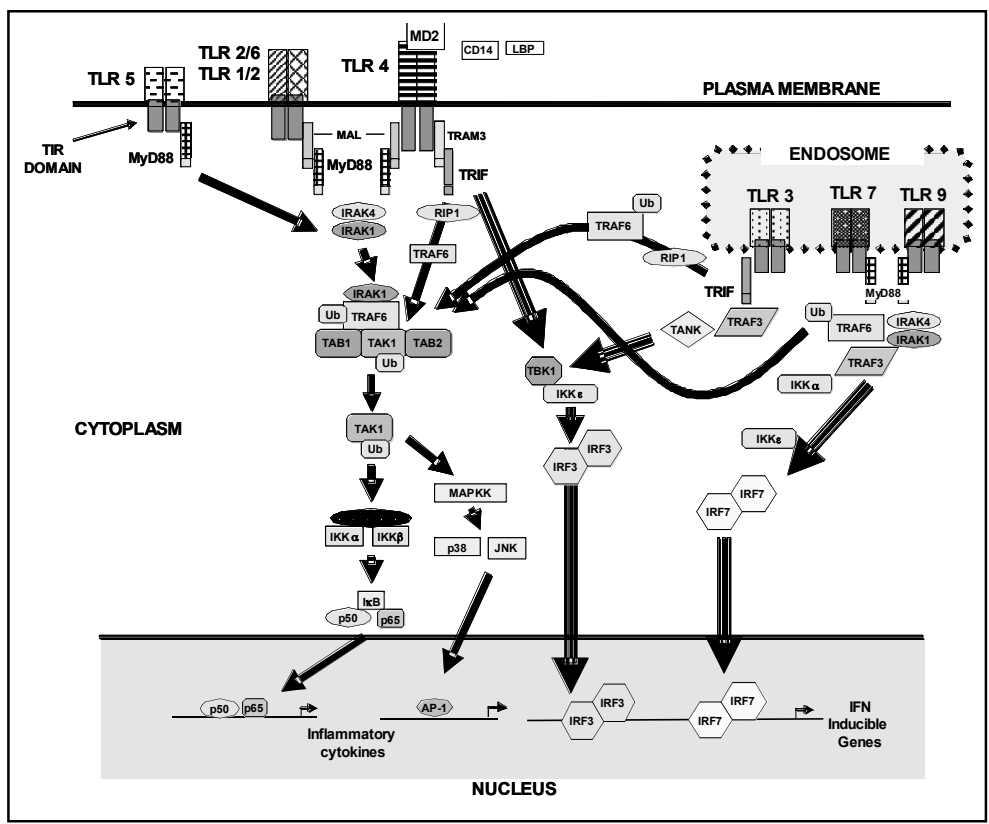

Fig. (1). TLR Signaling: Following stimulation, all TLRs activate a cascade of molecular interactions ultimately leading to gene activation by the transcription factors NFKB, AP1, IRF3 or IRF7. Activation by all TLRs except TLR3 recruits MyD88, IRAKs, and TRAF6 resulting in activation of TAK1 which activates the IKK complex and the MAPK pathway. Ultimately this pathway leads to IKB degradation and $\mathrm{NF \kappa B}$ translocation to the nucleus or activation of MAPKK with subsequent activation of AP1 which also induces proinflammatory cytokines and chemokines (solid arrow). TLR4, TLR1/2 and TLR2/6 require the adaptor protein MAL to activate the MyD88 pathway. TLR3 and TLR4 both recruit TRIF (via TRAM for TLR4) which activates TBK1 and IKKi causing IRF3 dimerization, nuclear translocation, and induction of IFNs and IFN inducible genes (striped arrow). In pDCs when endosomal TLR7 and TLR9 are stimulated, signaling is initiated through MyD88 to form a complex including TRAF6, TRAF3, IRAKs, IKK $\alpha$ leading to dimerization and nuclear translocation of IRF7 which also induces IFNs and activation of IFN inducible genes (striped arrow). Although variable in their ligand specificity, the signaling pathways share many adaptors and intermediate signaling proteins (adapted from [12-18]).

pathway whereas all others either use MyD88 only (TLR1/TLR2, TLR2/TLR6, TLR5, TLR7, TLR8, and TLR9) or just TRIF (TLR3) [13, 14, 17, 18]. TRIF serves as a bridge between activation of the NFKB pathway leading to proinflammatory cytokine production and the IRF3 pathway which leads to induction of IFN $\beta$. TRIF binds to receptor interacting protein 1 (RIP1) which recruits TRAF6 leading to activation of TAK1, the IKK complex and ultimately NFKB activation [45]. Several studies have demonstrated that NFKB activation through TRIF occurs later than that induced by the MyD88 pathway and is referred to as "late phase" NFKB activation in TLR4 signaling [15, 17, 40, 41]. TRIF also activates TRAF3 and TRAF-family member-associated NFKB activator (TANK) followed by TANK binding kinase 1 (TBK1). TBK1 interacts with IKKe resulting in phosphorylation of IRF3, a transcription factor that induces IFN $\beta$ and other IFN-inducible genes. A key point here is that the use of different adaptor proteins allows divergent signaling and divergent ligand binding by similar TLRs [12$14,16,17]$.

TLR3, TLR7, TLR8, and TLR9 are also transmembrane receptors that are expressed on the luminal side of endosomes with adaptor and signaling molecules in the cytoplasm. In addition to TLR3 and TLR4 mediated induction of IFN $\beta$, TLR7 and TLR9 are known to induce large amounts of IFN $\beta$ in plasmacytoid dendritic cells (pDCs). As stated above the ligands for TLR3, TLR7, and TLR9 are nucleic acids (Table 1) [12, 13, 16, 17]. Viruses are endocytosed and degraded leading to liberation of
dsRNA, ssRNA, and DNA which serve as ligands for TLR3, TLR7, and TLR9. TLR9 also can bind cytidine-phosphateguanine $(\mathrm{CpG})$ motifs from microbial DNA which are unmethylated (methylated in humans) and signal similarly $[13,17,40,41,46]$. TLR7 and TLR9 both require MyD88 for signaling leading to both $N F \kappa B$ activation and IFN $\beta$ induction which is markedly different from TLR3 and TLR4 in that TRIF is not required for IFN $\beta$ induction $[12,13,16$, 17]. In pDCs the transcription factor IRF7 is constitutively expressed and is activated by MyD88 dependent recruitment of IRAK1, 4, TRAF6, IKK, and TRAF3 [14, 15, 40, 41]. IRF7 then induces IFN $\beta$ and IFN-inducible proteins critical for antiviral innate immunity. TLR7 and TLR9 also activate the NFKB and MAPK pathways through MyD88. Other IRFs are reported to be involved in this type of signaling however their impact and specific functions are less well characterized [14, 17, 18, 40, 41].

The importance of TLRs and their signaling pathways is evident in the many reports of individuals (often children) afflicted by recurrent and severe infections who are found to have specific deficiencies, mutations, or polymorphisms of either TLRs or elements of their signaling pathways. Table 2 lists several such immunodeficiencies and elements of the resulting phenotype [39, 42, 47-65]. In some cases the phenotype is expected from the known biology of the protein in question. In other cases for instance, it is unclear how TLR4 polymorphism would lead to increased incidence of fungal infections. Conversely, redundancy in these signaling pathways is a likely explanation for a narrow phenotype 
Table 2: Pattern Recognition Receptor Related Immunodeficiencies

\begin{tabular}{|c|c|c|c|}
\hline IRAK-4 & Autosomal recessive & $\begin{array}{c}\text { Pyogenic infections (GPC mostly } \\
\text { with fewer GNR) }\end{array}$ & {$[47,63,64,166]$} \\
\hline IKK $\gamma(\mathrm{NEMO})$ & $\mathrm{X}$ linked recessive & $\begin{array}{l}\text { Pyogenic and mycobacterial } \\
\text { infections and some with fungal } \\
\text { and viral infections. }\end{array}$ & {$[47,48,62]$} \\
\hline MyD88 & Unknown & Pyogenic infections & {$[60]$} \\
\hline TLR3 & Autosomal dominant & Herpes Simplex Encephalitis & [59] \\
\hline UNC93B1 & Autosomal recessive & Herpes Simplex Encephalitis & {$[58]$} \\
\hline TLR2 & & Associated with tuberculosis & {$[51]$} \\
\hline TLR5 & & $\begin{array}{c}\text { Susceptibility to Legionella } \\
\text { pneumophila }\end{array}$ & {$[49,50,167]$} \\
\hline
\end{tabular}

characterized by pyogenic but not fungal, parasitic or mycobacterial infections in IRAK4 or MyD88 deficiencies [65]. As these genetic abnormalities become better characterized, no doubt more patients with deficiencies of the innate immune system and severe septic shock will be identified.

\section{CYTOSOLIC PATTERN RECOGNITION RECEP- TORS}

In addition to the transmembrane TLRs another group of PRRs located in the cytosol have been characterized. The two broad categories are called NOD-like receptors (NLRs) which detect cytosolic bacterial components and the retinoic acid-inducible gene 1 (RIG1) helicases which detect cytosolic viral components.

\section{NOD-like Receptors}

NLRs are comprised by a complex array of proteins that extend ligand binding diversity as well as providing an intracellular sensing mechanism to complement TLR function. If microbes slip past the extracellular and cell surface defenses, the cytosolic PRRs form a second line of defense to further protect the host. Ultimately, NLRs have a common target as do TLRs however the end products of NLR signaling is not the same for all NLRs. The major pathways activated are NFKB, MAPKs, and caspase 1 [66].

NLRs contain several functional domains including a series of LRRs which are key to ligand sensing, a central nucleotide domain (NACHT domain), and a signaling domain such as the caspase activation and recruitment domain (CARD), Pyrin domain (PYD), or baculovirus inhibitor repeat (BIR) domains (Fig. 2) [66-68]. LRRs are present in both TLRs and NLRs and participate in ligand sensing for a wide range of PAMPs either by direct binding or indirectly as appears to be the case for both TLR4 and the NLRs $[66,67]$. The NACHT domain is common to all NLRs and oligomerizes upon activation to form the high molecular weight complexes called signalosomes [66, 67]. CARD and PYD are death domain-fold proteins important in apoptosis and inflammation. The BIR domain consists of inhibitor of apoptosis (IAPs) and neuronal apoptosis inhibitor proteins (NAIPs). Therefore all NLRs are composed of an LRR at the $\mathrm{C}$ terminus, a NACHT domain in the center, and a death domain fold protein (CARD or PYD) or a BIR protein at the $N$ terminus [66-68].

There are 3 NLR subfamilies which include NALPs, IPAF, and NODs. As stated above each NLR has 3 domains and the 3 NLR subfamilies are classified by different LRRs and $\mathrm{N}$ terminus proteins but all have the central NACHT domain [66-68]. The NALPs have PYD domains at their N terminus where as the IPAF group has a CARD domain. The NOD family members all have CARD domains at their N terminus [66-68].

NOD1 and NOD2 are the best characterized NLRs to date. NOD1 detects $\gamma$-D-glutamyl-meso-diaminopimelic acid (iE-DAP) from Gram-negative bacteria and NOD2 detects muramyl dipeptide (MDP) which is a degradation product of PGN released by intracellular or phagocytosed bacteria (Table 1) $[17,18,67,69,70]$. Data is emerging to show that NOD1 may be capable of sensing cytosolic bacterial DNA from work with the intracellular pathogen Listeria monocytogenes [71]. When bound to ligand, NOD1 and NOD2 oligomerize and activate the adaptor protein and kinase RICK (Fig. 3) [17, 67]. This activation occurs via homophilic interaction between the CARD domains of the NODs with that of the RICK protein. RICK becomes polyubiquitinated and recruits TAK1 and NEMO resulting in NFKB activation leading to production of multiple 


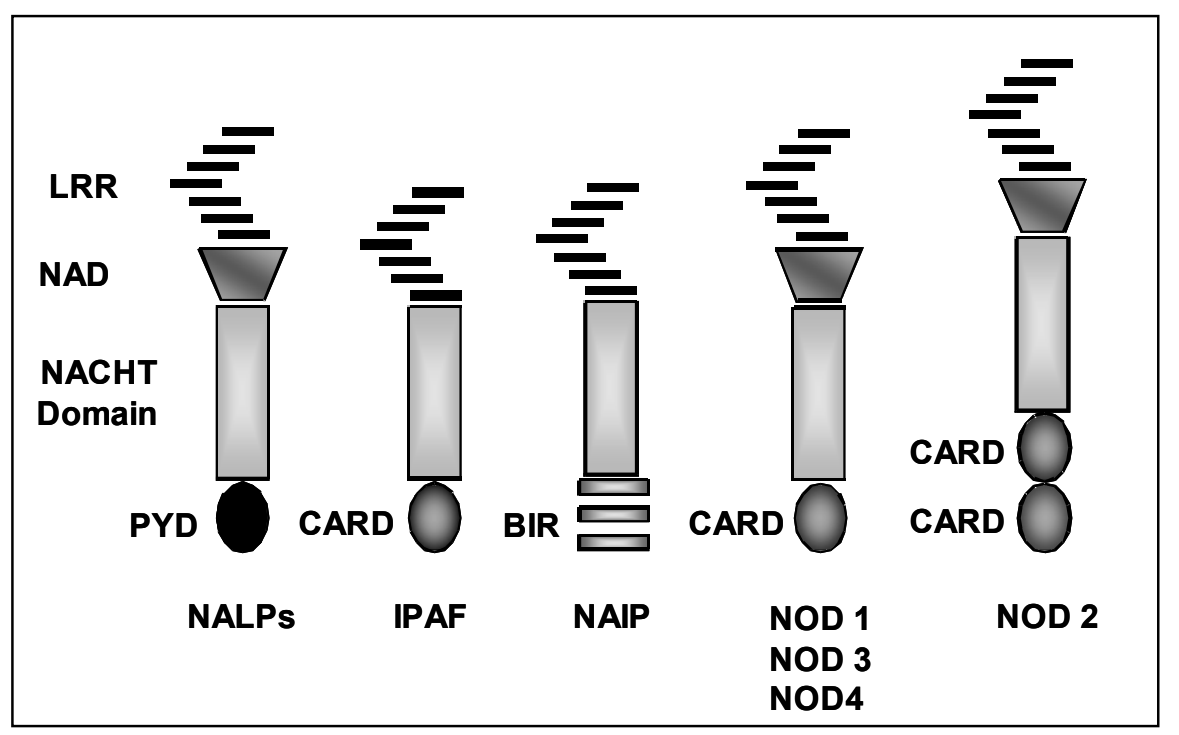

Fig. (2). NOD-like Receptors. NLRs are cytosolic PRRs capable of recognizing a wide range of cytosolic PAMPs. The 3 subtypes of NLRs include the NALPs, IPAF, and the NODs. Each have 3 domains consisting of a C terminal ligand sensing LRR domain, a central nucleotide domain (NACHT) with NACHT associated domains and either a PYD domain (NALPs), CARD domains (IPAF and NODs) or a BIR domain (NAIPs) at their $\mathrm{N}$ terminus (adapted from $[65,66]$ ).

proinflammatory cytokines [66]. Ligand binding by both NOD1 and NOD2 also leads to activation of MAPKs but the signaling pathway for this property is less well defined. NOD1 and NOD2 are expressed in phagocytes and in certain types of epithelial cells such as in the intestine [66].

Importantly, these NLRs are critical for clearance of the Helicobacter pylori and L. monocytogenes which are both phagocytosed and perforate the vacuolar membranes using distinct mechanisms [72, 73]. Once in the cytosol, $L$. monocytogenes replicates and induces IFN $\beta$ through NOD1 activation. The PAMP for this activation is thought to be bacterial DNA [73, 74]. H. pylori can inject PGN (component of bacterial cell wall) into the cytosol also leading to NOD1 activation and IFN $\beta$ production. In addition muramyl dipeptide found in digested $L$. monocytogenes, peptidoglycan is thought to potentiate NOD1 responses through activation of NOD2 [75-77]. Interplay between NOD receptors and TLRs is evident by the fact that LPS tolerized macrophages respond more vigorously to NOD2 agonists. In another context, NOD1 and NOD2 activation by agonists such as MDP and PGN can heighten subsequent responses to other TLR ligands including those for TLR4, TLR3, and TLR9 [78]. Furthermore, in the presence of LPS tolerance, clearance of the L. monocytogenes required both NOD1 and NOD2 [79]. In the intestine these molecules are particularly important in eradication of L. monocytogenes perhaps because of minimal expression of TLRs on gut epithelial cells [80].

Further functional relevance of these pathways has been demonstrated by an association between Crohn's disease and a NOD2 mutation and some association between atopy and NOD1 polymorphisms. A role for NOD1 in Crohn's disease is controversial and as yet not certain [17, 66, 67, 81-83]. Blau syndrome characterized by rashes, uveitis, and arthritis and Sarcoidosis are associated with a gain of function mutation of NOD2 [84]. At this point NOD deficiencies have not been implicated as contributing factors to severe septic shock or vulnerability to bacterial infection however with less common organisms such as L. monocytogenes, this system may in fact contribute.

\section{Inflammasomes}

NLR signaling via the NALP family and IPAF can lead to caspase 1 activation and production of the active form of IL- $1 \beta$ from its pro form by the formation of large macromolecules called inflammasomes (Fig. 4). Inflammasomes are comprised of large macromolecules including oligomerized NLR proteins and the apoptosis-associated speck-like protein containing a CARD (ASC). ASC is an adaptor protein that contains a PYD and a CARD. NALPs recruit ASC via PYD:PYD interaction and activate caspase 1 via homophilic interaction between the CARD domains of both ASC and caspase $1[13,17,18,66,67,85]$. There are 3 types of inflammasomes which are called NALP1, NALP3, and IPAF. These multimeric scaffold structures recruit and activate caspase 1 leading to the cleavage of bioactive IL- $1 \beta$ from pro IL-1 $\beta[66-68,85]$. The only known ligand for NALP1 currently is the anthrax lethal toxin from Bacillus anthracis [86]. NALP3 binds components of a diverse array of microbial pathogens such as L. monocytogenes, Staphylococcus aureus, bacterial and viral RNA and DNA (Table 1) [66, 67, 87, 88]. It also is activated by urate crystals which serve as endogenous danger signal as well as other foreign substances such as alum particles, silica, and asbestos $[89,90]$. Data is accumulating that suggests that many of these stimuli activate NALP3 indirectly by mechanisms including activation of NOD2, induction of potassium efflux from cells and induction of reactive oxygen species as a common pathway [90-92]. IPAF inflammasomes appear to be critical for caspase 1 activation (through an unknown mechanism) by bacteria that are intracellular and/or express flagellin including Salmonella typhimurium, Legionella pneumophila, Pseudomonas aeruginosa, and 


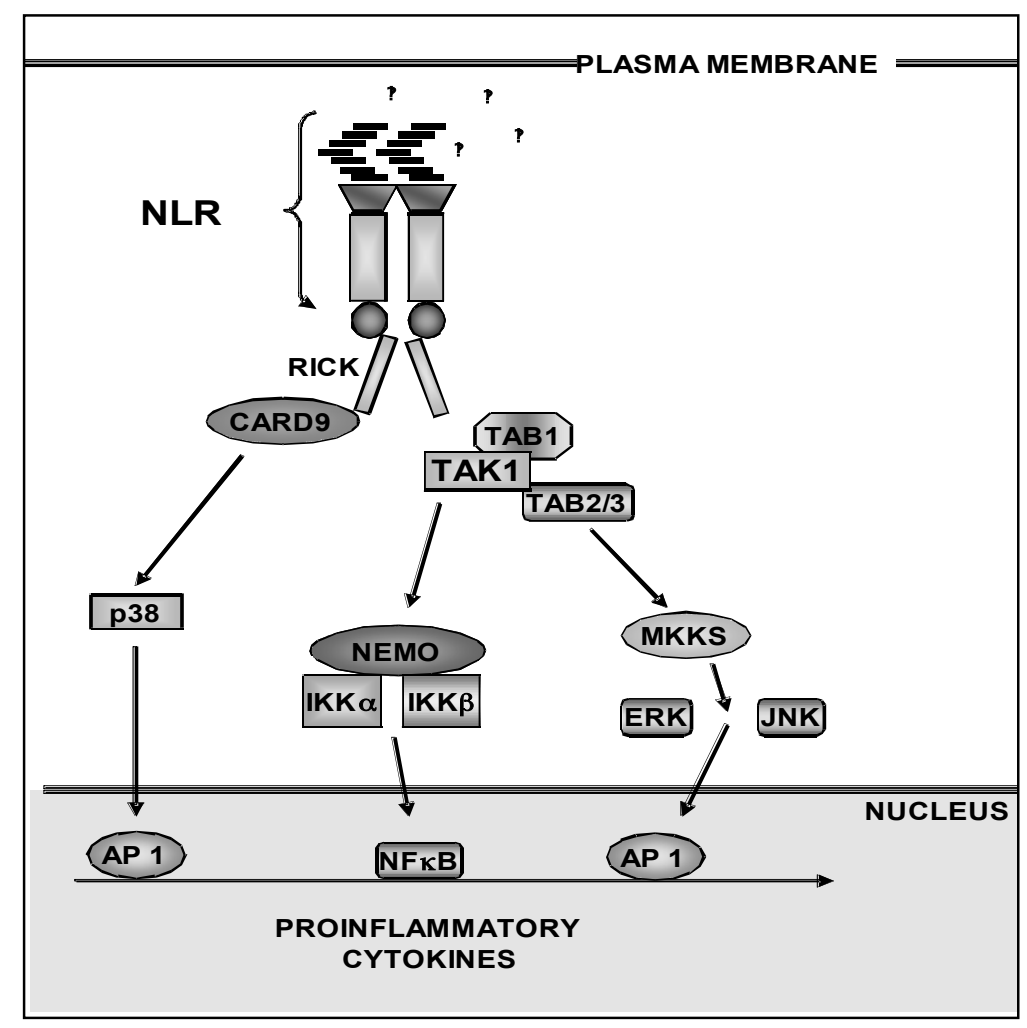

Fig. (3). NLR Signaling. When bound to ligands, NODs self oligomerize and activate the adaptor protein RICK via CARD:CARD interaction. RICK activates TAK1 leading to interaction with the IKK complex and activation of NFKB. NODs via RICK are also thought to activate MAPK pathways (adapted from $[65,66]$ ).

Shigella flexneri [66-68, 93-97]. Flagellin is secreted into the cytosol by bacteria specific secretion mechanisms. It appears that flagellin is a key activator of the IPAF inflammasome which is critical for caspase 1 activation and release of IL$1 \beta$ [98]. Although flagellin is also a TLR5 ligand, the impact of flagellin on IPAF is TLR5-independent $[66,96]$. Other NLRs have also been demonstrated to play a role in containment of $L$. pneumophila including NAIP5 [99, 100].

Clinical relevance has also been demonstrated for this group of NLRs and inflammasomes in hereditary autoinflammatory disorders characterized by excess IL- $1 \beta$ production. In contrast to deficiencies/mutations of TLRs and their signaling proteins, most disease processes related to NLRs are hyperinflammatory but do not predispose the host to frequent or catastrophic infections. Examples of such hyperinflammatory disorders include Muckle-Wells syndrome, familial cold auto-inflammatory syndrome in which NALP3 is mutated leading to excess IL- $1 \beta[67,101]$. Also, Familial Mediterranean Fever which occurs as a result of a Pyrin mutation $[67,101]$. Other diseases have been identified as likely falling into this category of syndromes based on their responsiveness to IL-1receptor antagonist therapy [102].

\section{RIG 1 Helicases}

Viruses can enter cells by endocytosis or fusion with the plasma membrane with subsequent entry into the cytoplasm where viral replication occurs. Since TLRs are transmembrane proteins cytosolic RNA (and DNA) cannot be detected by TLRs and instead can be detected by the cytosolic retinoic acid inducible gene 1 (RIG1)-like helicases (RLHs) including RIG1 and melanoma differentiationassociated gene 5 (MDA5) [40, 41, 46]. These proteins detect cytosolic RNA independent of TLRs. RLHs contain a $\mathrm{DExD} / \mathrm{H}$ box RNA helicase domain and 2 tandem CARD domains which are critical for downstream signaling (Fig. 5) $[40,41,46]$. Through the use of knock-out mice, it has become clear that RIG1 and MDA5 bind viral RNA from different viruses and as such demonstrate some elements of PAMP specificity (Table 1) [46, 103-105]. In addition these data demonstrate that the RLHs are not redundant in function. Activation of RLHs results in activation of IRF3, IRF7, and NFKB followed by transcription of IFN $\beta$ as well as inflammatory cytokines. Another protein called laboratory of genetics and physiology 2 (LGP2) is a third member of the RLH family which lacks the CARD domain which is necessary for initiating downstream signaling [40, 41, 46]. The exact role of this protein has not been elucidated but is thought to be a negative regulator of RIG1 and MDA5 because it can bind RNA but not signal $[17,106]$.

The helicase portion of the RLHs binds cytosolic RNA and "unwinds" it. The result of this conformational change is that the CARD domain becomes activated [106, 107]. Both activated RIG1 and MDA5 bind an adaptor protein called interferon $\mathrm{b}$ promoter stimulator 1 (IPS1) (also known as MAVS, VISA, and CARDIF) via CARD:CARD interaction $[17,106]$. It is this adaptor protein activation that serves as a bridge to the common downstream effector signaling pathways, IKKs to NFKB, and TBK1 to IRF3, and IRF7 leading to transcription of proinflammatory cytokines and 


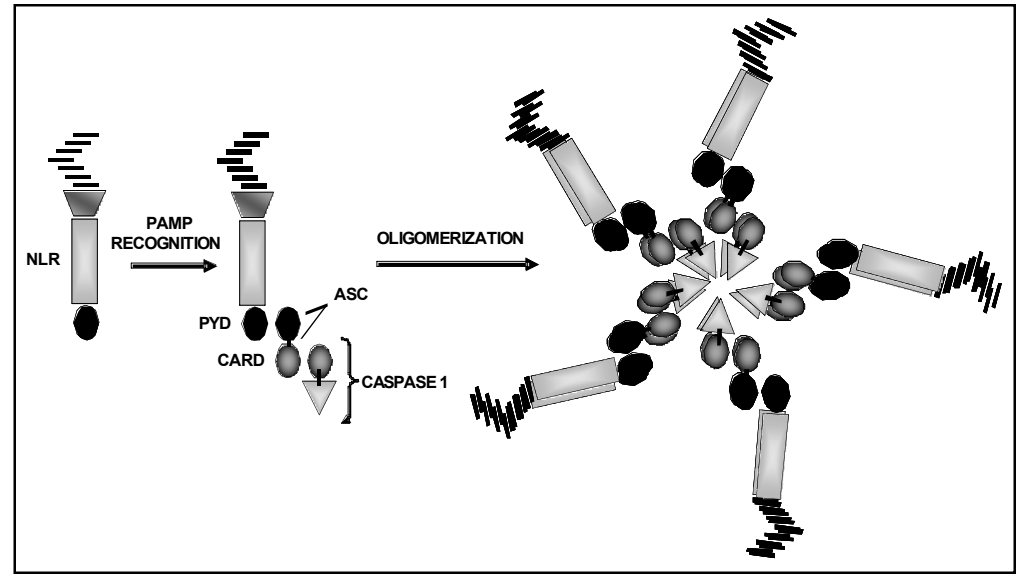

Fig. (4). Inflammasomes. NLRs (NALP1, NALP3, and IPAF) can serve as "scaffolding proteins" for the formation of large macromolecular complexes capable of caspase 1 activation and production of IL-1 $\beta$. Upon PAMP recognition, NALPs oligomerize and their PYD domain recruits the ASC adaptor protein via PYD:PYD interaction. ASC has an N terminal PYD and a C terminal CARD domain. When bound to NALP via PYD, the CARD domain of ASC interacts with the CARD domain of caspase 1 leading to cleavage of IL-1 $\beta$ from its proform. Inflammasomes are large multimers of such complexes. Because IPAF has a $\mathrm{C}$ terminal CARD domain, it does not require ASC and binds to caspase 1 directly (adapted from [66]).

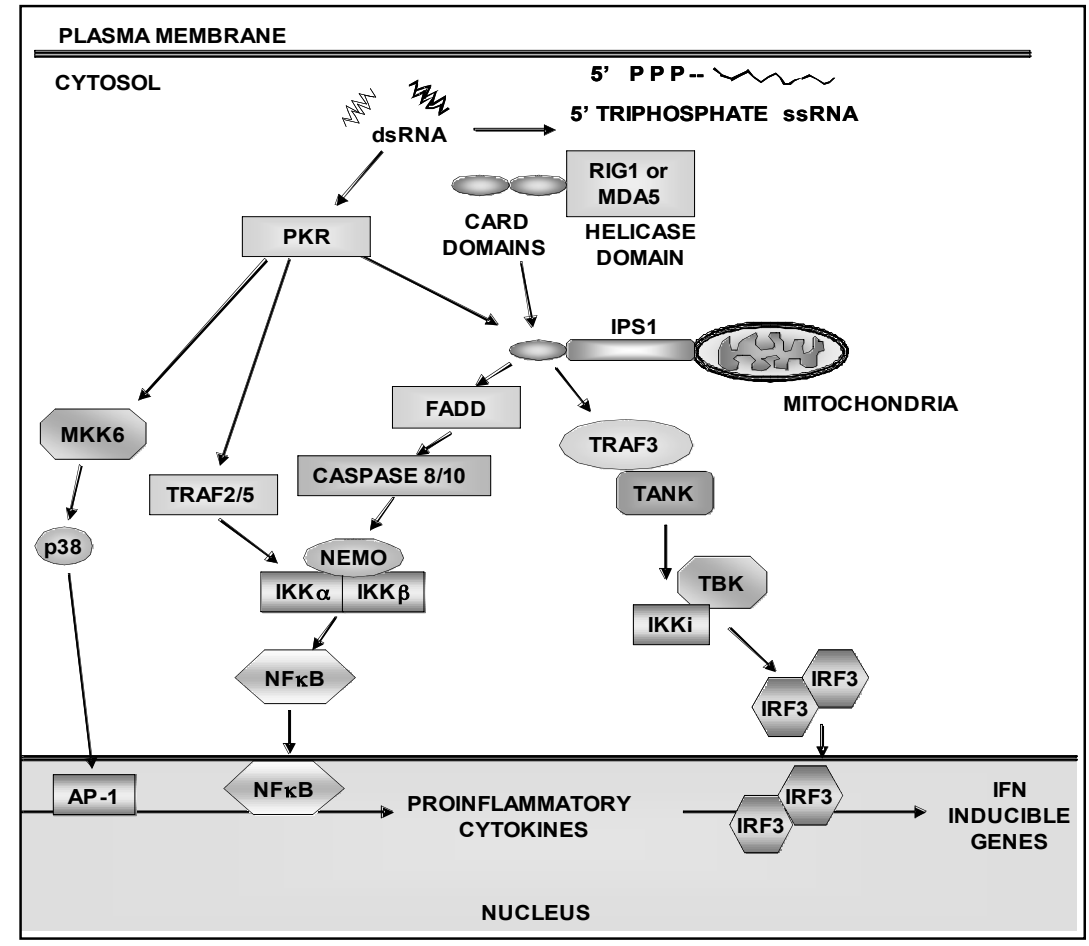

Fig. (5). Cytoplasmic Viral RNA Recognition. Viruses can enter cells by fusion with the plasma membrane or by endocytosis. RIG1 helicases are cyotosolic viral RNA specific PRRs. Their structure consists of a DExD/H box RNA helicase domain and 2 tandem CARD domains. The helicases RIG1 or MDA5 bind cytosolic dsRNA with $\mathrm{C}$ terminal 5' triphosphate moieties and unwind it. This results in activation of the CARD domains and binding to IPS via CARD:CARD homophilic interaction. IPS must be located on the outer mitochondrial membrane although the role of mitochondria in this process is unclear. IPS activation leads to activation of IRF3 through TBK1 and IKKi and NFKB through FADD, Caspase 8/10, and IKK. PKR is another cytosolic PRR that is activated by dsRNA and can activate NFKB, AP1, and IRF3. This cascade of signaling although independent of TLR signaling also leads to induction of proinflammatory mediators and IFN and IFN inducible genes (adapted from [12, 14, 40, 106]).

IFN $\beta[46,106]$. IPS1 is localized in the outer mitochondrial membrane. The contribution of the mitochondria to this process is not well defined however the interaction between IPS1 and mitochondria is critical for its function in the RLH pathway. IPS1 can activate the Fas-associated death domain protein (FADD) which associates with and cleaves caspase 10 and caspase 8 leading to NFKB activation [40, 108, 109].

The interferon inducible protein kinase (PKR) is another intracytoplasmic PRR that recognizes dsRNA and as such is important in defense against replicating viruses of many 
types. Upon activation by variable lengths of dsRNA, PKR autophosphorylates and phosphorylates the early initiation factor $2 \mathrm{~B}$ (eIF2B). This protein can inhibit the initiation of translation and by decreasing translation it can decrease viral replication $[18,106]$.

Since the cytosol has an abundance of cellular RNA, PRRs must discriminate between foreign RNA and self RNA. Self RNA is characterized by 5' monophosphate moieties but viral RNA has 5' triphosphate in this position. RIG1 detects the 5' triphosphate end of viral RNA but not the 5' monophosphate moiety of self RNA. PKR also can recognize 5' triphosphate single stranded tails on dsRNA. In this way, both RIG1 and PKR may contribute to distinguishing self from foreign RNA [110]. Other posttranscriptional differences in self RNA also contribute to discriminating self from non-self. One example is that viral RNA is commonly associated with various RNA binding proteins and this complex is recognized as non-self [110].

The pathways and RLRs responsible for recognition of cytosolic DNA are less clear and may involve other pathways since cells deficient in MyD88, TRIF, TLR9, MDA5, and RIG1 can produce IFN $\beta$ in response to DNA viruses and bacterial DNA in the cytoplasm [106]. An intracellular receptor called DNA-dependent activator of IRFs (DAI) is inducible by cytosolic DNA and can bind DNA leading to association with TBK1, and IRF3 followed by IFN production. Full characterization of this protein and its signaling pathway has yet to be completed and more work will be required to look for additional adaptors and regulators involved [106, 111].

\section{Scavenger Receptors}

Other PRRs have been characterized and are capable of extending the breadth of PAMP recognition [16-18]. One such group of PRRs are scavenger receptors which are best known for their ability to bind and internalize low density lipoproteins (LDLs) that are modified by oxidation or acetylation. Understanding of scavenger receptor biology has led to discovery of several subtypes including scavenger receptor A 1/11 (SR-A 1/11), macrophage receptor with collagenous domain (MARCO), and SR-B (CD 36) [16]. These PRRs also bind LTA, lipid A, and CpG DNA and to other types of polyanionic ligands from many microorganisms (Table 1) [16]. These receptors, like TLRs are highly conserved and have been shown to have overlapping function with some of the TLRs such as TLR2. One example is that SR-A 1/11 -/- mice exhibit heightened lethality and cytokine production in response to LPS indicating that SR-A $1 / 11$ modulates sensitivity to LPS $[112,113]$. Alternatively, mice with an SR-B mutation are more susceptible to gram positive cocci infection and they do not respond to diacylated TLR2 ligands indicating a possible cooperative function with TLR2 [16, 114].

\section{C- Type Lectin Receptors}

Carbohydrates on cell surfaces, circulating proteins, and pathogens can be recognized by $\mathrm{C}$-type lectin receptors (CLRs) on the surface of many cell types including dendritic cells, NK cells, macrophages, endothelial cells, and platelets. The carbohydrate recognition domain (CTLD) is highly conserved and denotes carbohydrate specificity [16]. CLRs are distinguishable by the type and number of CTLDs. Transmembrane CLRs can function as PRRs and are classified by their binding specificity into 2 groups. First are those in the mannose receptor family such as the mannose receptor (CD206) and second are those in the asialoglycoprotein receptor family including DC specific intercellular adhesion molecule-3-grabbing nonintegrin (DCSIGN) which is also known as (CD209) and dectin 1 (Table 1) [115]. Mannose, fucose, and glucan are the primary carbohydrates recognized by CLRs and this diversity of carbohydrate binding allows recognition of most types of pathogens [115]. Mannose is expressed by many viruses, fungi, mycobacteria. Fucose is expressed by certain bacteria and helminthes. Glucan is present on mycobacteria and fungi [115-117]. Upon binding to a CRL, PAMPs can be engulfed and degraded leading to antigen presentation by dendritic cells and macrophages to $\mathrm{T}$ cells $[16,115]$. CLR signaling proteins are vastly different from those used by TLRs. Some CLRs such as blood DC antigen 2 protein (BDCA2) activate intracellular signaling through immunoreceptor tyrosinebased activation motif (ITAM) containing molecules such as Fc Receptor $\gamma$ [118]. Others such as DC SIGN and Dectin 1 activate kinases and phosphatases through their cytoplasmic domains. Some CLRs such as Dectin 1 induce signaling independent of TLRs via activation of the spleen tyrosine kinase (Syk) and a serine/threonine kinase called Raf-1 leading to a complex relationship between noncanonical (Syk) and canonical NFkB activation (Raf-1). This ultimately results in a complex array of cytokines and chemokines important to $\mathrm{T}$ cell differentiation. Dectin-1 directs $\mathrm{T}$ helper cell differentiation controlling noncanonical NFKB activation through Raf-1 and Syk [119].

Other CLRs have been shown to negatively modulate TLR signaling and this appears to be dependent on pathogen specific carbohydrate signatures. Ligand binding to DCSIGN modulates TLR mediated activation of NFKB by TLR ligands. DC-SIGN binding activates the small GTPase Ras followed by Raf-1 which interacts with the p65 subunit of NFKB that was previously activated by the TLR cascade. Raf-1 phosphorylates p65 at serine 276 which becomes a target for acetylation by histone acetyltransferases CREB-binding protein (CBP) and p300. Acetylation at this site enhances and prolongs p65 DNA binding and transcription of anti-inflammatory cytokines such as IL-10. In this way DC-SIGN is able to negatively modulate TLR function. An example of a PAMP capable of modulating TLR activity in this way is the cell wall component mannose-capped lipoarabinomannam (ManLam) of Mycobacterium tuberculosis [115, 118, 120, 121].

Other CLRs such as BDCA2 and dendritic cells immunoreceptor (DCIR) can also downregulate TLR signaling by one of two mechanisms. Ligand binding by BDCA2 results in $\mathrm{Ca} 2+$ mobilization which through unknown mechanisms decreases TLR9 induction of IFN $\alpha$, TNF $\alpha$, and IL-6. DCIR when bound by ligand and endocytosed can activate its immunoreceptor tyrosine-based inhibitory motif (ITIM). This leads to recruitment of the negative regulatory phosphatases $\mathrm{SH}$-domain containing protein tyrosine phosphatase 1 (SHP1) or SHP2. Ultimately, downregulation of IL-12 and TNF $\alpha$ induced by TLR8 and 
IFN $\alpha$ induced by TLR9 in dendritic cells occurs [108, 109, $115,118]$.

The above paragraphs describe only some of the PRRs and signaling pathways used in the innate immune response. The PRRs and the signaling pathways described above demonstrate responsiveness to an enormous breadth of PAMP variability and origin. The versatility of PRRs is demonstrated by the responsiveness of cell surface and cytoplasmic receptors to PAMPs from a vast assortment of biochemical components, extracellular and intracellular location, entry sites in the body, and life cycles $[17,18]$. In addition, given the overlap in binding specificity to different aspects of pathogens, the spectrum of PRRs essentially assures that no single pathogen is sensed by only one type of PRR $[17,18]$. For instance a viral envelope particle may be sensed on the cell surface by a TLR however once inside the cytosol there are RLHs to provide a second tier of protection. In addition, data is accumulating to support the concept that there is overlap and/or cooperation between PRRs of different types leading to more effective pathogen defenses $[79,122,123]$. In this way the innate immune system has competently evolved to provide a rapid and potent inflammatory response while maintaining some specificity. This redundancy provides more protection against pathogens however it may confound efforts to interrupt inflammatory cascades activated in septic shock.

\section{PAMPs}

Microbial pathogen structure is tremendously diverse when considering the composition of viruses, bacteria, fungi, and parasites. PAMPs derived from these organisms become even more complex because many aspects of each microorganism can serve as a PAMP and be recognized by different PRRs. PAMPs are a diverse and complex array of molecular components including proteins, lipids, carbohydrates, DNA, and RNA. Some of the better characterized PAMPs and their interaction with their cognate PRRs are described below.

\section{Gram Positive Bacteria}

The structural scaffold of bacterial cell walls in both Gram-positive and Gram-negative bacteria is peptidoglycan (PGN) (Fig. 6). PGN is comprised of linear chains of alternating $\mathrm{N}$-acetylglucosamine and $\mathrm{N}$-acetylmuramic acid which are cross linked by peptide chains forming a large polymer. This macromolecule combined with glycolipids such as LTA and lipoproteins that are anchored in the cell membrane internal to PGN [18]. In Gram-positive bacteria the PGN layer is many fold thicker compared to that in the Gram-negative cell wall (Fig. 7) [13, 16, 124]. TLR2-/- mice exhibit significant susceptibility to the Gram positive organisms Streptococcal pneumoniae and S. aureus [17, 18, $125,126]$. Components of the Gram-positive cell wall that are recognized by TLR2 include LTA and lipoproteins. PGN had been considered a TLR2 ligand until the discovery of PGN-mediated activation of NOD2 by muramyl dipeptide which is a breakdown product of PGN. Recent data largely support PGN as a NOD2 agonist however it remains controversial. Recently, in an arthritis model, PGN signaled through TLR2 and NOD2 independently and by using
TLR2-/- and NOD2 -/- mice some overlap between the two has been demonstrated [127]. It is possible that this controversy is a result of impurities within the PGN preparations. For instance, macromolecular PGN activated signaling through TLR2 however monomeric PGN did not. In contrast signaling induced by monomeric PGN required NOD2 [128]. These authors suggested that perhaps the lipoproteins contained within the macromolecular preparation, were activating TLR2. It might also be possible that macromolecules signal through TLR2 on the cell surface and that monomeric preparations had access to the intracytoplasmic NOD2 receptor.

\section{Gram-Negative Bacteria}

In the Gram-negative bacterial cell wall a thin layer of PGN is sandwiched between the cell membrane and the outer membrane which contains LPS, phospholipids, and proteins (Fig. 7) [12, 13]. The lipid portion of LPS is called lipid $\mathrm{A}$ and is responsible for much of the immunostimulatory activity of LPS. Lipid A is attached to an O-linked polysaccharide via a core polysaccharide segment $[17,129,130]$. These components of LPS are not the same from all gram-negative bacteria and are distinguishable by variations in phosphorylation, acyl chains, number of monosaccharides, linkages, and fatty acid composition [1214]. These variations are very important to the immunostimulatory potency of the lipid A and LPS. One example of this is the reduced toxicity seen from monophosphoryl lipid A. To some degree these modifications determine pathogenicity and virulence $[14,17$, 130]. Some gram-negative bacteria can activate several PRRs simultaneously including TLR4 (LPS), TLR2 (lipoproteins), TLR5 and IPAF inflammasomes (flagellin), TLR9 (CpG DNA), and NOD1 and NOD2 (MDP). For instance, Neisseria meningitidis is capable of activating TLR2, 4 , and $9[13,131]$.

Other components of bacteria also serve as PAMPs including capsular structures, pili, flagella, and bacterial CpG DNA which are quite diverse between pathogens [16]. The capsule is important to prevent dessication, for adherence, and to prevent opsonization and is critical for virulence. TLRs and NLRs are involved in containment and the innate response to capsular material in S. pneumonia [132], N. meningitides [133], Haemophilus influenzae, and E. coli [134]. For example, clearance of encapsulated H. influenzae required TLR2, TLR4 and NOD1 signaling pathways [135]. Pili and fimbriae are long filamentous structures extending off the surface of many Gram-positive and Gram-negative bacteria with a variety of morphology and function and there are some data showing activation of TLR4 by fimbriae [136]. Flagella are important for bacterial motility in some Gram-negative and Gram-positive bacteria. Although flagellin is the key component of flagella, the structure can vary widely. Despite this it is a very potent stimulator of TLR5 and IPAF signaling [13, 14]. Some bacteria such as Salmonella are serotyped based on their LPS and flagellin subtypes $[14,94,95,120]$. Bacterial $\mathrm{CpG}$ dinucleotides are prevalent and unmethylated whereas mammalian $\mathrm{CpG}$ motifs are few and highly methylated. Only the unmethylated $\mathrm{CpG}$ is immunostimulatory. Single 


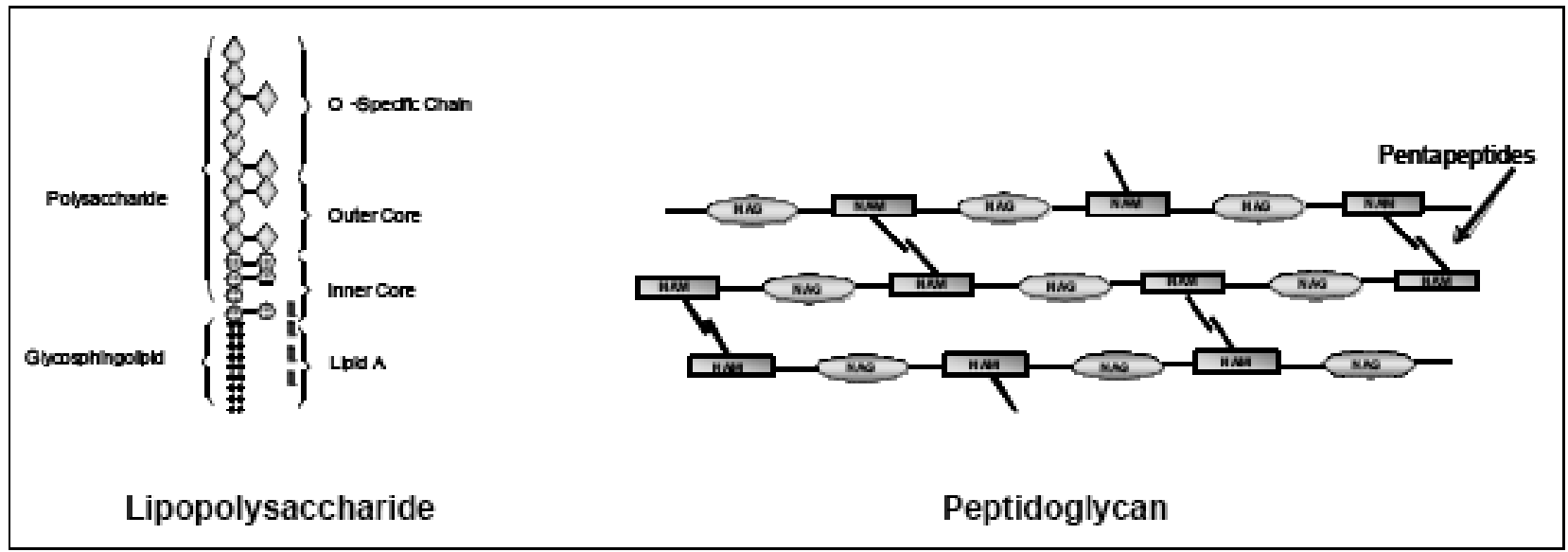

Fig. (6). Bacterial Cell Wall Components. A) Lipopolysaccharide is present in Gram negative bacteria and is anchored into the membrane by the lipid A component which is attached to a glycosidic chain with a monosaccharide core structure and a polysaccharide $\mathrm{O}$ chain. The lipid A moiety is the most immunopotent aspect of LPS. The O chain and core chains vary widely. Phosphate patterns, acyl chains, and fatty acid composition can affect toxicity of LPS. B) Peptidoglycan is the "structural scaffold" of the Gram positive and Gram negative bacterial cell wall. Highly conserved long glycan chains with alternating $\mathrm{N}$-acetyl glucosamine (NAG) and N-acetylmuramic acid (NAM) are cross linked by pentapeptide chains form this basis of this important structure (adapted from [15-17]).

stranded unmethlyated $\mathrm{CpG}$ regions are liberated by endosomal degradation of bacterial DNA and are recognized by TLR9 [13, 14, 137].

\section{Intracellular Bacteria}

Mycobacteria infect macrophages and replicate in phagosomes. Several components of mycobacteria are known to be PAMPs. There are several cell wall components from different subtypes of mycobacteria that can activate TLR2. For instance, the cell wall components lipomannan (LM) and lipoarabinomannan (LAM) (and derivatives) from M. tuberculosis are potent TLR2 ligands and most of the data show that TLR2/TLR1 heterodimers are responsive to LAM and mycobacterial lipoproteins [17, 33, 138, 139]. Despite these data, NOD2 and TLR2 double knockout mice controlled M. tuberculosis pneumonia efficiently suggesting that in vivo control of this organism is much more complex. CARD9 was recently shown to be critical in M. tuberculosis control suggesting that in vivo, this organism may activate multiple PRRs [140]. In leprosy, there is some evidence that TLR1/TLR2 expression is diminished on monocytes and DCs in lepromatous leprosy compared to tuberculoid leprosy suggesting a role for TLR1/2 in control of Mycobacterium leprae $[14,141,142]$.

The innate response to another intracellular bacteria $L$. pneumophila is not well defined however as mentioned previously its flagellin can activate signaling through Naip5/IPAF inflammasome and TLR5. In addition, RIG-1 and MDA5 appear to be activated by L. pneumophila and so far reports indicate that bacterial DNA and/or RNA are the activators of these pathways [143].

\section{Cell Wall Free Bacteria}

PAMPs from mycoplasma species, despite being devoid of a cell wall, have also been found to interact with PRRs. No endotoxins or exotoxins have been identified from Mycoplasma pneumoniae however lipid-associated mem- brane proteins (LAMPs) are capable of activating TLR1, TLR2, and partially TLR6. Such LAMPs are a subunit of the $\mathrm{F}_{0} \mathrm{~F}_{1}$-type ATPase and are diacylated [144]. In addition other triacylated lipoproteins signal through TLR 1 and 2 but are independent of TLR6 [145]. As expected by these data, an in vivo model of pulmonary mycoplasma infection is heavily reliant on TLR2 [146].

\section{Fungi}

Cell wall and cell surface components of many types of fungi have been identified as PAMPs and critical for eliciting inflammatory responses. Zymosan, mannan, phospholipomannan, and $\beta$ glucan are PAMPs expressed on a variety of important fungal pathogens including Candida albicans, Aspergillus fumigatus, and Cryptosporidia neoformans [147]. TLR2/6 heterodimers recognize zymosan, TLR2 homodimers recognize $\beta$ glucan, and phospholipomannan, and TLR4 recognizes mannan [13, 148-149]. In addition cooperation between types of PRRs has been demonstrated. One example is that dectin 1 and the mannose receptor can mediate phagocytosis of $\beta$ glucan which is followed by recruitment of TLR2 to the phagosome to elicit a strong inflammatory response $[13,14,35,150]$. All of the PAMPs listed above are expressed by $C$. albicans indicating that fungi present many PAMPs and require many types of PRR systems for infection control. Part of this complexity arises from the fact that different life stages present different PAMPs. Both yeast and filamentous forms of $C$. albicans can be seen during infection and $\beta$ glucan is present on the yeast form but not filamentous form. As a consequence, dectin 1 does not recognize the filamentous form resulting in enhanced virulence $[13,151]$

\section{Protozoa}

The study and recognition of PAMPs and PRR pathways involved in immune responses to parasitic infections has not advanced as quickly as it has for bacteria and viruses. Due to 


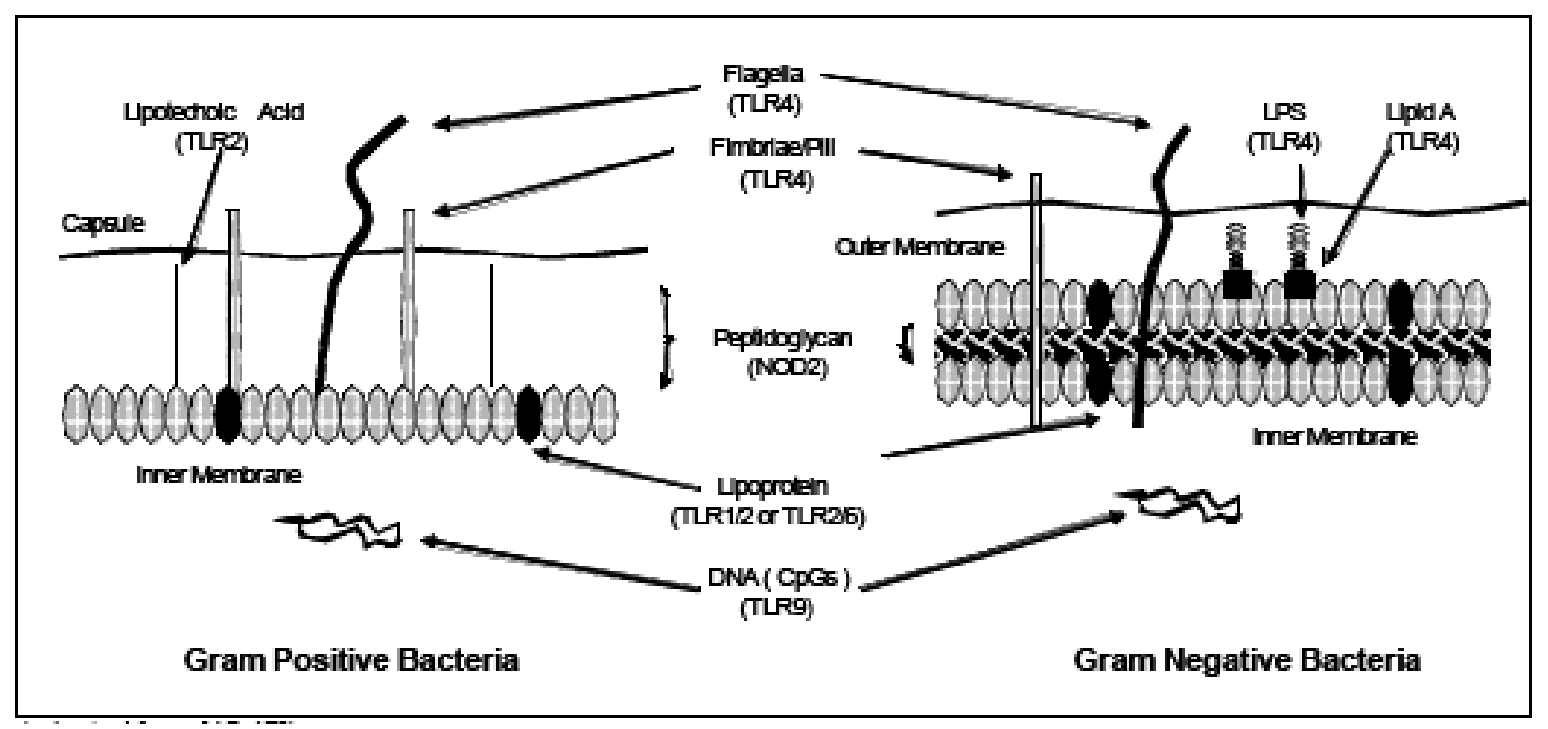

Fig. (7). Bacterial PAMPs and TLRs. The PGN layer of Gram positive bacterial cell wall is much thicker than that in the Gram negative cell wall. The Gram positive cell wall also consists of an inner cell wall with embedded lipoproteins and with polymers such as LTA linked to PGN extending outward. The Gram negative cell wall consists of a thinner PGN layer surrounded by an outer and an inner cell membrane also containing embedded lipoproteins. Other PAMPs include fimbriae (or Pili), flagellin, and bacterial DNA containing unmethylated CpG motifs (adapted from [15-17]).

the parasitic life cycle changes in morphology, study of the molecular requirements for the immune response is extremely complicated. Interactions and requirements of some PRRs have been defined for some protozoa. For example, interaction between profilin is a protein from Toxoplasma gondii and TLR11 is required for adequate induction of IL-12 which is essential for pathogen eradication [152, 153]. Another key finding is that the glycosylphosphatidylinositol (GPI) anchors present in many protozoa can activate TLR2 [154]. For Plasmodium falciparum, several PAMPs and PRRs have been defined. For example, the scavenger receptor CD36 and TLR2 work in concert to facilitate both internalization of infected erythrocytes and cytokine responses [155]. Also, hemozoin, a byproduct of hemoglobin digestion in malarial parasites serves as another PAMP and activates both NALP3 and TLR9 [156, 157]. The surface of helminths is very rich in glycoproteins and many are recognized by CLRs [158]. Control of Leishmania major requires TLR4 and MyD88 and the putative PAMP is lipophosphoglycan [159-161]. PAMPs from Trypanosome cruzi can be recognized by TLR2, TLR4, and TLR9 and MyD88 and TRIF deficiency results in significantly enhanced susceptibility to infection [162]. Many other PAMPs and PRR relationships have been defined for other helminths and some have unusual consequences. For example, the excretory/secretory (ES) glycoprotein ES-62 of the filarial nematode has been shown to signal through TLR4 but results in inhibition of proinflammatory cytokines [163]. Overall PRR and PAMP relationships critical for adequate responses to parasitic infection will no doubt progress much more slowly due to life cycle and structural complexities.

\section{Viruses}

There are several types of viral PAMPs that are critical for eliciting inflammatory and protective responses during viral infection. Some pathways lead to the production of inflammatory cytokines including TNF $\alpha$ through the NFKB pathway however the key innate antiviral cytokines are IFN $\beta$ and IFN $\alpha$ which are produced by an NFKB independent pathway. The IFNs are critical to viral defenses because they induce and activate a number of other antiviral proteins essential for viral containment. Viral PAMPs are virus specific and are recognized in a cell type specific fashion. DCs are key IFN producers and express the TLRs which induce IFNs strongly such as TLR3, TLR7, and TLR9 (as well as other TLRs) $[12,13]$. There are several sites at which some viral PAMPs are recognized. First are the viral envelope proteins including the fusion (F) protein from respiratory syncytial virus (RSV) which is recognized by TLR4 on the cell surface at contact with the virus and may be critical in preventing virus binding and entry processes $[13,164]$. In the cytosol and endosomes viral nucleic acids are recognized. The environment in which the host cell encounters viral nucleic acid reflects a specific subcellular distribution of PRRs [46]. When viruses are internalized into acidic endosomal compartments they can be uncoated exposing viral nucleic acids (DNA and ss or ds RNA) either by breakdown of infected/apoptotic cells or by viral replication $[13,45]$. dsRNA is a replicative intermediate for most viruses including both RNA and DNA viruses [13, 45]. In the endosome, it is recognized by TLR3 leading to IFN $\beta$ production [165]. TLR3 is expressed on numerous cell types including DCs, airway, vaginal, cervical, and intestinal epithelial cells as well as astrocytes indicating its importance in recognition of dsRNA from many viral types in many locations throughout the body [17]. TLR7 and TLR9 are also present in the endosome and recognize ssRNA and viral DNA rich in unmethylated $\mathrm{CpG}$ motifs. TLR7 and TLR9 are expressed almost exclusively in pDCs and are very potent stimuli for IFN $\beta$ induction [13, 43-45]. Many RNA viruses including influenza enter the cytosol through endosomes or directly through the cell surface and replicate there. In the 
cytosol viral RNA PAMPs are not recognized by TLRs but are recognized by RLHs which also lead to IFN production [43-45].

PAMPs known to activate PKR, another cytosolic PRR include long strands of dsRNA and more recently identified modified RNA containing 5' triphosphate extensions of dsRNA. Such motifs are not expressed in mammalian RNA thereby allowing PKR to distinguish between self and foreign RNA [44-46, 106]. Again as with the other classes of PAMPs described above, viruses present multiple PAMPs that require both TLR-dependent and TLR-independent PRR pathways for proper control [110].

\section{CONCLUSION}

The primary purpose of PRRs is to recognize non-self PAMPs and to initiate an immune response against them. Many studies have demonstrated that a relatively small number of PRRs can recognize the vastly differing biochemical structures of PAMPs from different types of microorganisms as well as different life stages. In many cases, several PRR pathways are activated by different PAMPs from the same pathogens thereby providing depth and redundancy to the innate immune response. In addition, it appears that different PRR pathways can cooperate to elicit more potent inflammatory responses than each individually. An example of which is the cooperation between NLRs and TLRs in response to PGN. In some cases the distribution of PRRs is cell type specific and subcellular compartmentspecific again providing more depth in the recognition of diverse PAMP structures and pathogen life cycles. Finally, there is a great deal of overlap in signaling pathways and end products of such signaling. Examples include the use of MyD88, TRAF6, and NFאB to elicit multiple inflammatory cytokines from multiple PRR pathways. Production of IFNs and IFN-inducible proteins is another common endpoint for multiple pathways and this is largely as a result of IRF3 and IRF7 signaling. In the end the role of PRRs is not only recognition and initiation of inflammatory responses but also to present antigens to $T$ cells for initiation of the adaptive immune response to further provide protection from current as well as future encounters with such pathogens.

During septic shock, many of these PRRs are activated by PAMPs from the infecting organism triggering the inflammatory cascade. Early in the clinical course of septic shock, exaggerated inflammatory response are associated with poor outcomes. Mortality from septic shock remains unacceptably high and in order to continue to improve outcomes, a better understanding of host pathogen interactions is essential in order to understand the sites of action of potential therapies. In the pediatric population where the immune response is maturing and defenses are heavily reliant on the innate immune response, research in this area is particularly important.

\section{REFERENCES}

[1] Watson RS, Carcillo JA. Scope and epidemiology of pediatric sepsis. Pediatr Crit Care Med 2005; 6(3 Suppl): S3-5.

[2] Watson RS, Carcillo JA, Linde-Zwirble WT, et al. The epidemiology of severe sepsis in children in the United States. Am J Respir Crit Care Med 2003; 167(5): 695-701.

[3] Vincent JL, Abraham E. The last 100 years of sepsis. Am J Respir Crit Care Med 2006; 173(3): 256-63.
[4] Dombrovskiy VY, Martin AA, Sunderram J, Paz HL. Facing the challenge: decreasing case fatality rates in severe sepsis despite increasing hospitalizations. Crit Care Med 2005; 33(11): 2555-62.

[5] Wong HR, Cvijanovich N, Wheeler DS, et al. Interleukin-8 as a stratification tool for interventional trials involving pediatric septic shock. Am J Respir Crit Care Med 2008; 178(3): 276-82.

[6] Sprong T, van der Ven-Jongekrijg J, Neeleman C, van der Meer JW, van Deuren M. Influence of innate cytokine production capacity on clinical manifestation and severity of pediatric meningococcal disease. Crit Care Med 2009; 37(10): 2812-8.

[7] Sullivan JS, Kilpatrick L, Costarino AT, Jr., Lee SC, Harris MC. Correlation of plasma cytokine elevations with mortality rate in children with sepsis. J Pediatr 1992; 120(4 Pt 1): 510-5.

[8] Nowak JE, Wheeler DS, Harmon KK, Wong HR. Admission chemokine (C-C motif) ligand 4 levels predict survival in pediatric septic shock. Pediatr Crit Care Med 2010; 11(2): 213-6.

[9] Hatherill M, Tibby SM, Turner C, Ratnavel N, Murdoch IA. Procalcitonin and cytokine levels: relationship to organ failure and mortality in pediatric septic shock. Crit Care Med 2000; 28(7): 2591-4.

[10] Doughty L, Carcillo JA, Kaplan S, Janosky J. The compensatory anti-inflammatory cytokine interleukin 10 response in pediatric sepsis-induced multiple organ failure. Chest 1998; 113(6): 162531 .

[11] Carrol ED, Thomson AP, Jones AP, Jeffers G, Hart CA. A predominantly anti-inflammatory cytokine profile is associated with disease severity in meningococcal sepsis. Intensive Care Med 2005; 31(10): 1415-9.

[12] Takeuchi O, Akira S. Pattern recognition receptors and inflammation. Cell 2010; 140(6): 805-20.

[13] Miyake K. Innate immune sensing of pathogens and danger signals by cell surface Toll-like receptors. Semin Immunol 2007; 19(1): 310 .

[14] Kawai T, Akira S. TLR signaling. Semin Immunol 2007; 19(1): 2432 .

[15] Akira S, Takeda K. Toll-like receptor signalling. Nat Rev Immunol 2004; 4(7): 499-511.

[16] Pluddemann A, Mukhopadhyay S, Gordon S. The interaction of macrophage receptors with bacterial ligands. Expert Rev Mol Med 2006; 8(28): 1-25.

[17] Akira S, Uematsu S, Takeuchi O. Pathogen recognition and innate immunity. Cell 2006; 124(4): 783-801.

[18] Mogensen TH. Pathogen recognition and inflammatory signaling in innate immune defenses. Clin Microbiol Rev 2009; 22(2): 240-73, Table of Contents.

[19] Wynn J, Cornell TT, Wong HR, Shanley TP, Wheeler DS. The host response to sepsis and developmental impact. Pediatrics 2010; 125(5): 1031-41.

[20] Wynn JL, Levy O. Role of innate host defenses in susceptibility to early-onset neonatal sepsis. Clin Perinatol 2010; 37(2): 307-37.

[21] Forster-Waldl E, Sadeghi K, Tamandl D, et al. Monocyte toll-like receptor 4 expression and LPS-induced cytokine production increase during gestational aging. Pediatr Res 2005; 58(1): 121-4.

[22] Levy O, Zarember KA, Roy RM, et al. Selective impairment of TLR-mediated innate immunity in human newborns: neonatal blood plasma reduces monocyte TNF-alpha induction by bacterial lipopeptides, lipopolysaccharide, and imiquimod, but preserves the response to R-848. J Immunol 2004; 173(7): 4627-34.

[23] Belderbos ME, van Bleek GM, Levy O, et al. Skewed pattern of Toll-like receptor 4-mediated cytokine production in human neonatal blood: low LPS-induced IL-12p70 and high IL-10 persist throughout the first month of life. Clin Immunol 2009; 133(2): 22837.

[24] Wynn JL, Scumpia PO, Delano MJ, et al. Increased mortality and altered immunity in neonatal sepsis produced by generalized peritonitis. Shock 2007; 28(6): 675-83.

[25] Proulx F, Joyal JS, Mariscalco MM, et al. The pediatric multiple organ dysfunction syndrome. Pediatr Crit Care Med 2009; (1): 1222.

[26] Kutko MC, Calarco MP, Flaherty MB, et al. Mortality rates in pediatric septic shock with and without multiple organ system failure. Pediatr Crit Care Med 2003; 4(3): 333-7.

[27] Barsness KA, Bensard DD, Partrick DA, et al. Endotoxin induces an exaggerated interleukin-10 response in peritoneal macrophages 
of children compared with adults. J Pediatr Surg 2004; 39(6): 9125; discussion -5 .

[28] Barsness KA, Bensard DD, Partrick DA, et al. IL-1beta induces an exaggerated pro- and anti-inflammatory response in peritoneal macrophages of children compared with adults. Pediatr Surg Int 2004; 20(4): 238-42.

[29] Hartel C, Adam N, Strunk T, et al. Cytokine responses correlate differentially with age in infancy and early childhood. Clin Exp Immunol 2005; 142(3): 446-53.

[30] Fitzgerald KA, O'Neill LA. The role of the interleukin-1/Toll-like receptor superfamily in inflammation and host defence. Microbes Infect 2000; 2(8): 933-43.

[31] Hoebe K, Georgel P, Rutschmann S, et al. CD36 is a sensor of diacylglycerides. Nature 2005; 433(7025): 523-7.

[32] Jimenez-Dalmaroni MJ, Xiao N, Corper AL, et al. Soluble CD36 ectodomain binds negatively charged diacylglycerol ligands and acts as a co-receptor for TLR2. PLoS One 2009; 4(10): e7411.

[33] Drage MG, Pecora ND, Hise AG, et al. TLR2 and its co-receptors determine responses of macrophages and dendritic cells to lipoproteins of Mycobacterium tuberculosis. Cell Immunol 2009; 258(1): 29-37.

[34] Vasselon T, Detmers PA, Charron D, Haziot A. TLR2 recognizes a bacterial lipopeptide through direct binding. J Immunol 2004; 173(12): 7401-5.

[35] Gantner BN, Simmons RM, Canavera SJ, Akira S, Underhill DM. Collaborative induction of inflammatory responses by dectin-1 and Toll-like receptor 2. J Exp Med 2003; 197(9): 1107-17.

[36] Hirschfeld M, Ma Y, Weis JH, Vogel SN, Weis JJ. Cutting edge: repurification of lipopolysaccharide eliminates signaling through both human and murine toll-like receptor 2. J Immunol 2000; 165(2): 618-22.

[37] Wakelin SJ, Sabroe I, Gregory CD, et al. "Dirty little secrets"-endotoxin contamination of recombinant proteins. Immunol Lett 2006; 106(1): 1-7.

[38] Tsan MF, Baochong G. Pathogen-associated molecular pattern contamination as putative endogenous ligands of Toll-like receptors. J Endotoxin Res 2007; 13(1): 6-14.

[39] Ku CL, Yang K, Bustamante J, et al. Inherited disorders of human Toll-like receptor signaling: immunological implications. Immunol Rev 2005; 203; 10-20.

[40] Kawai T, Akira S. Antiviral signaling through pattern recognition receptors. J Biochem 2007; 141(2): 137-45.

[41] Kawai T, Akira S. Toll-like receptor and RIG-I-like receptor signaling. Ann N Y Acad Sci 2008; 1143; 1-20.

[42] Picard $\mathrm{C}$, von Bernuth $\mathrm{H}, \mathrm{Ku} \mathrm{CL}$, et al. Inherited human IRAK-4 deficiency: an update. Immunol Res 2007; 38(1-3): 347-52.

[43] Cook DN, Pisetsky DS, Schwartz DA. Toll-like receptors in the pathogenesis of human disease. Nat Immunol 2004; 5(10): 975-9.

[44] Suzuki N, Chen NJ, Millar DG, et al. IL-1 receptor-associated kinase 4 is essential for IL-18-mediated NK and Th1 cell responses. J Immunol 2003; 170(8): 4031-5.

[45] Meylan E, Burns K, Hofmann K, et al. RIP1 is an essential mediator of Toll-like receptor 3-induced NF-kappa B activation. Nat Immunol 2004; 5(5): 503-7.

[46] Saito T, Gale M, Jr. Principles of intracellular viral recognition. Curr Opin Immunol 2007; 19(1): 17-23.

[47] Vogel SN, Awomoyi AA, Rallabhandi P, Medvedev AE. Mutations in TLR4 signaling that lead to increased susceptibility to infection in humans: an overview. J Endotoxin Res 2005; 11(6): 333-9.

[48] Ku CL, Picard C, Erdos M, et al. IRAK4 and NEMO mutations in otherwise healthy children with recurrent invasive pneumococcal disease. J Med Genet 2007; 44(1): 16-23.

[49] Hawn TR, Verbon A, Lettinga KD, et al. A common dominant TLR5 stop codon polymorphism abolishes flagellin signaling and is associated with susceptibility to legionnaires' disease. J Exp Med 2003; 198(10): 1563-72.

[50] Hawn TR, Berrington WR, Smith IA, et al. Altered inflammatory responses in TLR5-deficient mice infected with Legionella pneumophila. J Immunol 2007; 179(10): 6981-7.

[51] Ogus AC, Yoldas B, Ozdemir T, et al. The Arg753GLn polymorphism of the human toll-like receptor 2 gene in tuberculosis disease. Eur Respir J 2004; 23(2): 219-23.

[52] Awomoyi AA, Rallabhandi P, Pollin TI, et al. Association of TLR4 polymorphisms with symptomatic respiratory syncytial virus infection in high-risk infants and young children. J Immunol 2007; 179(5): 3171-7.

[53] Tal G, Mandelberg A, Dalal I, et al. Association between common Toll-like receptor 4 mutations and severe respiratory syncytial virus disease. J Infect Dis 2004; 189(11): 2057-63.

[54] Pamer EG. TLR polymorphisms and the risk of invasive fungal infections. N Engl J Med 2008; 359(17): 1836-8.

[55] Agnese DM, Calvano JE, Hahm SJ, et al. Human toll-like receptor 4 mutations but not CD14 polymorphisms are associated with an increased risk of gram-negative infections. J Infect Dis 2002; 186(10): 1522-5.

[56] Lorenz E, Mira JP, Frees KL, Schwartz DA. Relevance of mutations in the TLR4 receptor in patients with gram-negative septic shock. Arch Intern Med 2002; 162(9): 1028-32.

[57] Arbour NC, Lorenz E, Schutte BC, et al. TLR4 mutations are associated with endotoxin hyporesponsiveness in humans. Nat Genet 2000; 25(2): 187-91.

[58] Casrouge A, Zhang SY, Eidenschenk C, et al. Herpes simplex virus encephalitis in human UNC-93B deficiency. Science 2006; 314(5797): 308-12.

[59] Zhang SY, Jouanguy E, Ugolini S, et al. TLR3 deficiency in patients with herpes simplex encephalitis. Science 2007; 317(5844): 1522-7.

[60] von Bernuth H, Picard C, Jin Z, et al. Pyogenic bacterial infections in humans with MyD88 deficiency. Science 2008; 321(5889): 6916.

[61] Courtois G, Smahi A, Reichenbach J, et al. A hypermorphic IkappaBalpha mutation is associated with autosomal dominant anhidrotic ectodermal dysplasia and $\mathrm{T}$ cell immunodeficiency. J Clin Invest 2003; 112(7): 1108-15.

[62] Orange JS, Geha RS. Finding NEMO: genetic disorders of NF[kappa]B activation. J Clin Invest 2003; 112(7): 983-5.

[63] Currie AJ, Davidson DJ, Reid GS, et al. Primary immunodeficiency to pneumococcal infection due to a defect in Toll-like receptor signaling. J Pediatr 2004; 144(4): 512-8.

[64] Medvedev AE, Lentschat A, Kuhns DB, et al. Distinct mutations in IRAK-4 confer hyporesponsiveness to lipopolysaccharide and interleukin-1 in a patient with recurrent bacterial infections. J Exp Med 2003; 198(4): 521-31.

[65] Suhir H, Etzioni A. The role of Toll-like receptor signaling in human immunodeficiencies. Clin Rev Allergy Immunol 2010; 38(1): 11-9.

[66] Chen G, Shaw MH, Kim YG, Nunez G. NOD-like receptors: role in innate immunity and inflammatory disease. Annu Rev Pathol 2009; 4; 365-98.

[67] Martinon F, Mayor A, Tschopp J. The inflammasomes: guardians of the body. Annu Rev Immunol 2009; 27; 229-65.

[68] Martinon F, Burns K, Tschopp J. The inflammasome: a molecular platform triggering activation of inflammatory caspases and processing of proIL-beta. Mol Cell 2002; 10(2): 417-26.

[69] Girardin SE, Boneca IG, Viala J, et al. Nod2 is a general sensor of peptidoglycan through muramyl dipeptide (MDP) detection. J Biol Chem 2003; 278(11): 8869-72.

[70] Chamaillard M, Hashimoto M, Horie Y, et al. An essential role for NOD1 in host recognition of bacterial peptidoglycan containing diaminopimelic acid. Nat Immunol 2003; 4(7): 702-7.

[71] Soulat D, Bauch A, Stockinger S, Superti-Furga G, Decker T. Cytoplasmic Listeria monocytogenes stimulates IFN-beta synthesis without requiring the adapter protein MAVS. FEBS Lett 2006; 580(9): 2341-6.

[72] Viala J, Chaput C, Boneca IG, et al. Nod1 responds to peptidoglycan delivered by the Helicobacter pylori cag pathogenicity island. Nat Immunol 2004; 5(11): 1166-74.

[73] Portnoy DA, Jacks PS, Hinrichs DJ. Role of hemolysin for the intracellular growth of Listeria monocytogenes. J Exp Med 1988; 167(4): 1459-71.

[74] O'Riordan M, Yi CH, Gonzales R, Lee KD, Portnoy DA. Innate recognition of bacteria by a macrophage cytosolic surveillance pathway. Proc Natl Acad Sci USA 2002; 99(21): 13861-6.

[75] Boneca IG, Dussurget O, Cabanes D, et al. A critical role for peptidoglycan N-deacetylation in Listeria evasion from the host innate immune system. Proc Natl Acad Sci USA 2007; 104(3): 997-1002. 
[76] Leber JH, Crimmins GT, Raghavan S, et al. Distinct TLR- and NLR-mediated transcriptional responses to an intracellular pathogen. PLoS Pathog 2008; 4(1): e6.

[77] Watanabe T, Asano N, Fichtner-Feigl S, et al. NOD1 contributes to mouse host defense against Helicobacter pylori via induction of type I IFN and activation of the ISGF3 signaling pathway. J Clin Invest 2010; 120(5): 1645-62.

[78] Tada H, Aiba S, Shibata K, Ohteki T, Takada H. Synergistic effect of Nod1 and Nod2 agonists with toll-like receptor agonists on human dendritic cells to generate interleukin-12 and T helper type 1 cells. Infect Immun 2005; 73(12): 7967-76.

[79] Kim YG, Park JH, Shaw MH, et al. The cytosolic sensors Nod1 and Nod2 are critical for bacterial recognition and host defense after exposure to Toll-like receptor ligands. Immunity 2008; 28(2): 246-57.

[80] Kobayashi KS, Chamaillard M, Ogura Y, et al. Nod2-dependent regulation of innate and adaptive immunity in the intestinal tract. Science 2005; 307(5710): 731-4.

[81] Mitchell JA, Paul-Clark MJ, Clarke GW, McMaster SK, Cartwright N. Critical role of toll-like receptors and nucleotide oligomerisation domain in the regulation of health and disease. J Endocrinol 2007; 193(3): 323-30.

[82] Murillo LS, Morre SA, Pena AS. Role of the CARD15 gene in the pathogenesis of Crohn disease: phenotypic classification and prognostic implications. Scand J Gastroenterol 2003; 38(11): 1107 14.

[83] Abreu MT, Fukata M, Arditi M. TLR signaling in the gut in health and disease. J Immunol 2005; 174(8): 4453-60.

[84] Okafuji I, Nishikomori R, Kanazawa N, et al. Role of the NOD2 genotype in the clinical phenotype of Blau syndrome and earlyonset sarcoidosis. Arthritis Rheum 2009; 60(1): 242-50.

[85] Kanneganti TD, Lamkanfi M, Nunez G. Intracellular NOD-like receptors in host defense and disease. Immunity 2007; 27(4): 54959.

[86] Boyden ED, Dietrich WF. Nalp1b controls mouse macrophage susceptibility to anthrax lethal toxin. Nat Genet 2006; 38(2): 240-4.

[87] Kanneganti TD, Body-Malapel M, Amer A, et al. Critical role for Cryopyrin/Nalp3 in activation of caspase-1 in response to viral infection and double-stranded RNA. J Biol Chem 2006; 281(48): 36560-8.

[88] Ichinohe T, Pang IK, Iwasaki A. Influenza virus activates inflammasomes via its intracellular M2 ion channel. Nat Immunol 2010; 11(5): 404-10.

[89] Eisenbarth SC, Colegio OR, O'Connor W, Sutterwala FS, Flavell RA. Crucial role for the Nalp3 inflammasome in the immunostimulatory properties of aluminium adjuvants. Nature 2008; 453(7198): 1122-6.

[90] Dostert C, Petrilli V, Van Bruggen R, et al. Innate immune activation through Nalp3 inflammasome sensing of asbestos and silica. Science 2008; 320(5876): 674-7.

[91] Petrilli V, Papin S, Dostert C, et al. Activation of the NALP3 inflammasome is triggered by low intracellular potassium concentration. Cell Death Differ 2007; 14(9): 1583-9.

[92] Martinon F, Agostini L, Meylan E, Tschopp J. Identification of bacterial muramyl dipeptide as activator of the NALP3/cryopyrin inflammasome. Curr Biol 2004; 14(21): 1929-34.

[93] Mariathasan S, Newton K, Monack DM, et al. Differential activation of the inflammasome by caspase-1 adaptors ASC and Ipaf. Nature 2004; 430(6996): 213-8.

[94] Amer A, Franchi L, Kanneganti TD, et al. Regulation of Legionella phagosome maturation and infection through flagellin and host Ipaf. J Biol Chem 2006; 281(46): 35217-23.

[95] Franchi L, Amer A, Body-Malapel M, et al. Cytosolic flagellin requires Ipaf for activation of caspase-1 and interleukin 1beta in salmonella-infected macrophages. Nat Immunol 2006; 7(6): 57682.

[96] Miao EA, Alpuche-Aranda CM, Dors M, et al. Cytoplasmic flagellin activates caspase-1 and secretion of interleukin 1beta via Ipaf. Nat Immunol 2006; 7(6): 569-75.

[97] Franchi L, Stoolman J, Kanneganti TD, et al. Critical role for Ipaf in Pseudomonas aeruginosa-induced caspase-1 activation. Eur J Immunol 2007; 37(11): 3030-9.

[98] Lamkanfi M, Dixit VM. Inflammasomes: guardians of cytosolic sanctity. Immunol Rev 2009; 227(1): 95-105.
[99] Ren T, Zamboni DS, Roy CR, Dietrich WF, Vance RE. Flagellindeficient Legionella mutants evade caspase-1- and Naip5-mediated macrophage immunity. PLoS Pathog 2006; 2(3): e18.

[100] Zamboni DS, Kobayashi KS, Kohlsdorf T, et al. The Bircle cytosolic pattern-recognition receptor contributes to the detection and control of Legionella pneumophila infection. Nat Immunol 2006; 7(3): 318-25.

[101] Henderson C, Goldbach-Mansky R. Monogenic IL-1 mediated autoinflammatory and immunodeficiency syndromes: finding the right balance in response to danger signals. Clin Immunol 2010; 135(2): 210-22.

[102] Mitroulis I, Skendros P, Ritis K. Targeting IL-1beta in disease; the expanding role of NLRP3 inflammasome. Eur J Intern Med 2010; 21(3): 157-63.

[103] Gitlin L, Barchet W, Gilfillan S, et al. Essential role of mda-5 in type I IFN responses to polyriboinosinic:polyribocytidylic acid and encephalomyocarditis picornavirus. Proc Natl Acad Sci USA 2006; 103(22): 8459-64.

[104] Kato H, Takeuchi O, Sato S, et al. Differential roles of MDA5 and RIG-I helicases in the recognition of RNA viruses. Nature 2006; 441(7089): 101-5.

[105] Kato H, Sato S, Yoneyama M, et al. Cell type-specific involvement of RIG-I in antiviral response. Immunity 2005; 23(1): 19-28.

[106] Unterholzner L, Bowie AG. The interplay between viruses and innate immune signaling: recent insights and therapeutic opportunities. Biochem Pharmacol 2008; 75(3): 589-602.

[107] Marques JT, Devosse T, Wang D, et al. A structural basis for discriminating between self and nonself double-stranded RNAs in mammalian cells. Nat Biotechnol 2006; 24(5): 559-65.

[108] Meyer-Wentrup F, Cambi A, Joosten B, et al. DCIR is endocytosed into human dendritic cells and inhibits TLR8-mediated cytokine production. J Leukoc Biol 2009; 85(3): 518-25.

[109] Meyer-Wentrup F, Benitez-Ribas D, Tacken PJ, et al. Targeting DCIR on human plasmacytoid dendritic cells results in antigen presentation and inhibits IFN-alpha production. Blood 2008; 111(8): 4245-53.

[110] Nallagatla SR, Toroney R, Bevilacqua PC. A brilliant disguise for self RNA: 5'-end and internal modifications of primary transcripts suppress elements of innate immunity. RNA Biol 2008; 5(3): 1404.

[111] Takaoka A, Wang Z, Choi MK, et al. DAI (DLM-1/ZBP1) is a cytosolic DNA sensor and an activator of innate immune response. Nature 2007; 448(7152): 501-5.

[112] Bowdish DM, Gordon S. Conserved domains of the class A scavenger receptors: evolution and function. Immunol Rev 2009; 227(1): 19-31.

[113] Haworth R, Platt N, Keshav S, et al. The macrophage scavenger receptor type $\mathrm{A}$ is expressed by activated macrophages and protects the host against lethal endotoxic shock. J Exp Med 1997; 186(9): 1431-9.

[114] Sutcliffe IC, Russell RR. Lipoproteins of gram-positive bacteria. J Bacteriol 1995; 177(5): 1123-8.

[115] Geijtenbeek TB, Gringhuis SI. Signalling through C-type lectin receptors: shaping immune responses. Nat Rev Immunol 2009; 9(7): 465-79.

[116] van Kooyk Y, Rabinovich GA. Protein-glycan interactions in the control of innate and adaptive immune responses. Nat Immunol 2008; 9(6): 593-601.

[117] Rothfuchs AG, Bafica A, Feng CG, et al. Dectin-1 interaction with Mycobacterium tuberculosis leads to enhanced IL-12p40 production by splenic dendritic cells. J Immunol 2007; 179(6): 3463-71.

[118] Kerrigan AM, Brown GD. Syk-coupled C-type lectin receptors that mediate cellular activation via single tyrosine based activation motifs. Immunol Rev 2010; 234(1): 335-52.

[119] Gringhuis SI, den Dunnen J, Litjens M, et al. Dectin-1 directs T helper cell differentiation by controlling noncanonical NF-kappaB activation through Raf-1 and Syk. Nat Immunol 2009; 10(2): 20313.

[120] Gringhuis SI, den Dunnen J, Litjens M, et al. C-type lectin DCSIGN modulates Toll-like receptor signaling via Raf-1 kinasedependent acetylation of transcription factor NF-kappaB. Immunity 2007; 26(5): 605-16. 
[121] Geijtenbeek TB, Van Vliet SJ, Koppel EA, et al. Mycobacteria target DC-SIGN to suppress dendritic cell function. J Exp Med 2003; 197(1): 7-17.

[122] Fritz JH, Girardin SE, Fitting C, et al. Synergistic stimulation of human monocytes and dendritic cells by Toll-like receptor 4 and NOD1 - and NOD2-activating agonists. Eur J Immunol 2005; 35(8): 2459-70.

[123] van Heel DA, Ghosh S, Butler M, et al. Synergistic enhancement of Toll-like receptor responses by NOD1 activation. Eur J Immunol 2005; 35(8): 2471-6.

[124] Scheffers DJ, Pinho MG. Bacterial cell wall synthesis: new insights from localization studies. Microbiol Mol Biol Rev 2005; 69(4): 585-607.

[125] Echchannaoui H, Frei K, Schnell C, et al. Toll-like receptor 2deficient mice are highly susceptible to Streptococcus pneumoniae meningitis because of reduced bacterial clearing and enhanced inflammation. J Infect Dis 2002; 186(6): 798-806.

[126] Takeuchi O, Hoshino K, Akira S. Cutting edge: TLR2-deficient and MyD88-deficient mice are highly susceptible to Staphylococcus aureus infection. J Immunol 2000; 165(10): 53926.

[127] Rosenzweig HL, Jann MJ, Vance EE, et al. Nucleotide-binding oligomerization domain 2 and Toll-like receptor 2 function independently in a murine model of arthritis triggered by intraarticular peptidoglycan. Arthritis Rheum 2010; 62(4): 1051-9.

[128] Volz T, Nega M, Buschmann J, et al. Natural Staphylococcus aureus-derived peptidoglycan fragments activate NOD2 and act as potent costimulators of the innate immune system exclusively in the presence of TLR signals. FASEB J 2010; 241(10): 4089-102.

[129] Backhed F, Normark S, Schweda EK, Oscarson S, RichterDahlfors A. Structural requirements for TLR4-mediated LPS signalling: a biological role for LPS modifications. Microbes Infect 2003; 5(12): 1057-63.

[130] Caroff M, Karibian D. Structure of bacterial lipopolysaccharides. Carbohydr Res 2003; 338(23): 2431-47.

[131] Mogensen TH, Paludan SR, Kilian M, Ostergaard L. Live Streptococcus pneumoniae, Haemophilus influenzae, and Neisseria meningitidis activate the inflammatory response through Toll-like receptors 2, 4, and 9 in species-specific patterns. J Leukoc Biol 2006; 80(2): 267-77.

[132] van Rossum AM, Lysenko ES, Weiser JN. Host and bacterial factors contributing to the clearance of colonization by Streptococcus pneumoniae in a murine model. Infect Immun 2005; 73(11): 7718-26.

[133] Pluddemann A, Mukhopadhyay S, Sankala M, et al. SR-A, MARCO and TLRs differentially recognise selected surface proteins from Neisseria meningitidis: an example of fine specificity in microbial ligand recognition by innate immune receptors. $\mathbf{J}$ Innate Immun 2009; 1(2): 153-63.

[134] Metkar S, Awasthi S, Denamur E, et al. Role of CD14 in responses to clinical isolates of Escherichia coli: effects of $\mathrm{K} 1$ capsule expression. Infect Immun 2007; 75(11): 5415-24.

[135] Zola TA, Lysenko ES, Weiser JN. Mucosal clearance of capsuleexpressing bacteria requires both TLR and nucleotide-binding oligomerization domain 1 signaling. J Immunol 2008; 181(11): 7909-16.

[136] Sirard JC, Bayardo M, Didierlaurent A. Pathogen-specific TLR signaling in mucosa: mutual contribution of microbial TLR agonists and virulence factors. Eur J Immunol 2006; 36(2): 260-3.

[137] Krieg AM. CpG motifs in bacterial DNA and their immune effects. Annu Rev Immunol 2002; 20; 709-60.

[138] Tapping RI, Tobias PS. Mycobacterial lipoarabinomannan mediates physical interactions between TLR1 and TLR2 to induce signaling. J Endotoxin Res 2003; 9(4): 264-8.

[139] Yoshida A, Inagawa H, Kohchi C, Nishizawa T, Soma G. The role of toll-like receptor 2 in survival strategies of Mycobacterium tuberculosis in macrophage phagosomes. Anticancer Res 2009; 29(3): 907-10.

[140] Dorhoi A, Desel C, Yeremeev V, et al. The adaptor molecule CARD9 is essential for tuberculosis control. J Exp Med 2010; 207(4): 777-92.

[141] Malhotra D, Relhan V, Reddy BS, Bamezai R. TLR2 Arg677Trp polymorphism in leprosy: revisited. Hum Genet 2005; 116(5): 4135 .
[142] Krutzik SR, Ochoa MT, Sieling PA, et al. Activation and regulation of Toll-like receptors 2 and 1 in human leprosy. Nat Med 2003; 9(5): 525-32.

[143] Monroe KM, McWhirter SM, Vance RE. Identification of host cytosolic sensors and bacterial factors regulating the type I interferon response to Legionella pneumophila. PLoS Pathog 2009; 5(11): e1000665.

[144] Shimizu T, Kida Y, Kuwano K. A dipalmitoylated lipoprotein from Mycoplasma pneumoniae activates NF-kappa B through TLR1, TLR2, and TLR6. J Immunol 2005; 175(7): 4641-6.

[145] Shimizu T, Kida Y, Kuwano K. Triacylated lipoproteins derived from Mycoplasma pneumoniae activate nuclear factor-kappaB through toll-like receptors 1 and 2. Immunology 2007; 121(4): 47383.

[146] Love W, Dobbs N, Tabor L, Simecka JW. Toll-like receptor 2 (TLR2) plays a major role in innate resistance in the lung against murine mycoplasma. PLoS One 2010; 5(5): e10739.

[147] Roeder A, Kirschning CJ, Rupec RA, Schaller M, Korting HC. Toll-like receptors and innate antifungal responses. Trends Microbiol 2004; 12(1): 44-9.

[148] Netea MG, Van Der Graaf CA, Vonk AG, et al. The role of tolllike receptor (TLR) 2 and TLR4 in the host defense against disseminated candidiasis. J Infect Dis 2002; 185(10): 1483-9.

[149] Ozinsky A, Underhill DM, Fontenot JD, et al. The repertoire for pattern recognition of pathogens by the innate immune system is defined by cooperation between toll-like receptors. Proc Natl Acad Sci USA 2000; 97(25): 13766-71.

[150] Underhill DM, Ozinsky A, Hajjar AM, et al. The Toll-like receptor 2 is recruited to macrophage phagosomes and discriminates between pathogens. Nature 1999; 401(6755): 811-5.

[151] Gantner BN, Simmons RM, Underhill DM. Dectin-1 mediates macrophage recognition of Candida albicans yeast but not filaments. EMBO J 2005; 24(6): 1277-86.

[152] Yarovinsky F. Toll-like receptors and their role in host resistance to Toxoplasma gondii. Immunol Lett 2008; 119(1-2): 17-21.

[153] Yarovinsky F, Zhang D, Andersen JF, et al. TLR11 activation of dendritic cells by a protozoan profilin-like protein. Science 2005; 308(5728): 1626-9.

[154] Gazzinelli RT, Ropert C, Campos MA. Role of the Toll/interleukin-1 receptor signaling pathway in host resistance and pathogenesis during infection with protozoan parasites. Immunol Rev 2004; 201; 9-25.

[155] Erdman LK, Cosio G, Helmers AJ, et al. CD36 and TLR interactions in inflammation and phagocytosis: implications for malaria. J Immunol 2009; 183(10): 6452-9.

[156] Coban C, Ishii KJ, Kawai T, et al. Toll-like receptor 9 mediates innate immune activation by the malaria pigment hemozoin. J Exp Med 2005; 201(1): 19-25.

[157] Dostert C, Guarda G, Romero JF, et al. Malarial hemozoin is a Nalp3 inflammasome activating danger signal. PLoS One 2009; 4(8): e6510.

[158] Perrigoue JG, Marshall FA, Artis D. On the hunt for helminths: innate immune cells in the recognition and response to helminth parasites. Cell Microbiol 2008; 10(9): 1757-64.

[159] de Veer MJ, Curtis JM, Baldwin TM, et al. MyD88 is essential for clearance of Leishmania major: possible role for lipophosphoglycan and Toll-like receptor 2 signaling. Eur J Immunol 2003; 33(10): 2822-31.

[160] Kropf P, Freudenberg MA, Modolell M, et al. Toll-like receptor 4 contributes to efficient control of infection with the protozoan parasite Leishmania major. Infect Immun 2004; 72(4): 1920-8.

[161] Revaz-Breton M, Ronet C, Ives A, et al. The MyD88 protein 88 pathway is differently involved in immune responses induced by distinct substrains of Leishmania major. Eur J Immunol 2010; 40(6): 1697-707.

[162] Koga R, Hamano S, Kuwata H, et al. TLR-dependent induction of IFN-beta mediates host defense against Trypanosoma cruzi. J Immunol 2006; 177(10): 7059-66.

[163] Goodridge HS, Marshall FA, Else KJ, et al. Immunomodulation via novel use of TLR4 by the filarial nematode phosphorylcholinecontaining secreted product, ES-62. J Immunol 2005; 174(1): 28493.

[164] Kurt-Jones EA, Popova L, Kwinn L, et al. Pattern recognition receptors TLR4 and CD14 mediate response to respiratory syncytial virus. Nat Immunol 2000; 1(5): 398-401. 
[165] Alexopoulou L, Holt AC, Medzhitov R, Flavell RA. Recognition of double-stranded RNA and activation of NF-kappaB by Toll-like receptor 3. Nature 2001; 413(6857): 732-8.

[166] Picard C, Puel A, Bonnet M, et al. Pyogenic bacterial infections in humans with IRAK-4 deficiency. Science 2003; 299(5615): 20769.
[167] Morris AE, Liggitt HD, Hawn TR, Skerrett SJ. Role of Toll-like receptor 5 in the innate immune response to acute $\mathrm{P}$. aeruginosa pneumonia. Am J Physiol Lung Cell Mol Physiol 2009; 297(6): L1112-9.

(C) Lesley Doughty; Licensee Bentham Open.

This is an open access article licensed under the terms of the Creative Commons Attribution Non-Commercial License (http://creativecommons.org/licenses/by-nc/3.0/) which permits unrestricted, non-commercial use, distribution and reproduction in any medium, provided the work is properly cited. 